\title{
Deep-mixing and deep-cooling events in Lake Garda: Simulation and mechanisms
}

\author{
Bouke Biemond, ${ }^{1 *}$ Marina Amadori, ${ }^{2,3}$ Marco Toffolon, ${ }^{2}$ Sebastiano Piccolroaz, ${ }^{4}$ Hans van Haren, ${ }^{5}$ Henk A. Dijkstra ${ }^{1}$ \\ ${ }^{1}$ Institute for Marine and Atmospheric research Utrecht, Department of Physics, Utrecht University, the Netherlands; ${ }^{2}$ Department \\ of Civil, Environmental and Mechanical Engineering, University of Trento, Italy; ${ }^{3}$ Institute for Electromagnetic Sensing of the \\ Environment, National Research Council, Milan, Italy; ${ }^{4}$ Physics of Aquatic Systems Laboratory (APHYS) - Margaretha Kamprad \\ Chair, École Polytechnique Fédérale de Lausanne, Switzerland; ${ }^{5}$ Royal Netherlands Institute for Sea Research (NIOZ), the \\ Netherlands
}

\begin{abstract}
A calibrated three-dimensional numerical model (Delft3D) and in-situ observations are used to study the relation between deepwater temperature and deep mixing in Lake Garda (Italy). A model-observation comparison indicates that the model is able to adequately capture turbulent kinetic energy production in the surface layer and its vertical propagation during unstratified conditions. From the modeling results several processes are identified to affect the deep-water temperature in Lake Garda. The first process is thermocline tilting due to strong and persistent winds, leading to a temporary disappearance of stratification followed by vertical mixing. The second process is turbulent cooling, which acts when vertical temperature gradients are nearly absent over the whole depth and arises as a combination of buoyancy-induced turbulence production due to surface cooling and turbulence production by strong winds. A third process is differential cooling, which causes cold water to move from the shallow parts of the lake to deeper parts along the sloping bottom. Two of these processes (thermocline tilting and turbulent cooling) cause deep-mixing events, while deep-cooling events are mainly caused by turbulent cooling and differential cooling. Detailed observations of turbulence quantities and lake temperature, available at the deepest point of Lake Garda for the year 2018, indicate that differential cooling was responsible for the deep-water cooling at that location. Long-term simulations of deep-water temperature and deep mixing appear to be very sensitive to the applied wind forcing. This sensitivity is one of the main challenges in making projections of future occurrences of episodic deep mixing and deep cooling under climate change.
\end{abstract}

\section{INTRODUCTION}

Deep temperate lakes can be divided into three classes. Holomictic lakes undergo a complete overturning each year, meromictic lakes show a quasi-permanent stratification, and oligomictic lakes sometimes undergo episodes of complete overturning. Such overturning events are often accompanied by increased vertical mixing at (nearbottom) depths, as seen by turbulent kinetic energy dissipation rates that are orders of magnitude above the long-term mean. Hence, these events are also called Deep-

Corresponding author: w.t.biemond@uu.nl

Keywords: Turbulence modelling in lakes; deep mixing; climate change.

Edited by: Diego Fontaneto, CNR-IRSA Water Research Institute, Verbania, Italy.

Received: 1 March 2021

Accepted: 21 April 2021.

This work is licensed under a Creative Commons Attribution NonCommercial 4.0 License (CC BY-NC 4.0).

${ }^{\circ}$ Copyright: the Author(s), 2021

Licensee PAGEPress, Italy

J. Limnol., 2021; 80(2):2010

DOI: 10.4081/jlimnol.2021.2010
Mixing Events (DMEs; Crawford and Collier, 1997). The intensity of vertical mixing is important for a lake and its ecological status (Imboden et al., 1983; Goldman and Jassby, 1990). Indeed, vertical mixing enables nutrients to be transported from deep waters to the surface and oxygen in opposite direction (Salmaso et al., 2002). Since biological primary production occurs mostly in the euphotic zone close to the surface, the supply of nutrients from the deep hypolimnion affects the entire ecosystem of a lake. This is particularly true for deep lakes, which store significantly more nutrients in the hypolimnion compared to shallow lakes where the nutrients input from the catchment is predominant (Schwefel et al., 2019). Moreover, the development of anoxic conditions at the water-sediment interface, due to reduced downward oxygen fluxes, triggers the release of nutrients from the bottom sediments (Hupfer and Lewandowski, 2008).

Among deep peri-alpine lakes, there are several examples where the enrichment of nutrients in the euphotic zone and the replenishment of deep-water oxygen are intimately linked to DMEs. Vertical mixing was found to strongly affect the deep- water oxygen concentration in Lake Zurich (North et al., 2014), Lake Geneva (Schwefel et al., 2016) and the deep subalpine lakes in Northern Italy (Rogora et al., 2018). It was also found to be crucial for the trophic state of Lake Constance (Straile et al., 2003) and Lake Iseo (Salmaso et al., 2002; Lau et al., 2020) and for the phytoplankton composition in Lake Lugano (Simona, 2003). For Lake Lugano, Lepori et al. (2018), also ascribed the change 
of the deep-mixing intensity to the failure of the restoration attempts. Exceptional winter mixing events were found to be mainly responsible for turnover of nutrients in Lake Geneva (Krishna et al., 2021), and for deep-water renewal in Lake Lugano (Holzner et al., 2009). By comparing multi-annual trends of hypolimnetic water temperature and oxygen concentrations in Lake Iseo (Valerio et al., 2015), also surprisingly high oxygen concentrations were identified at depth during such mixing events.

Most of the above mentioned studies warn that the ongoing global warming will reduce the occurrence of DMEs in terms of frequency and intensity. A warming climate increases thermal stratification and lake stability and reduces the number of cold winters. Both these aspects contribute to reduce the occurrence of buoyancy-driven turbulence by surface cooling (Fenocchi et al., 2018; Rogora et al., 2018; Schwefel et al., 2019), one of the dominant mechanisms of DMEs. Recent projections of lake water temperature profiles worldwide (Woolway and Merchant, 2019) indicate that (in the next century) the mixing regime of many lakes will be altered by climate change through a reduction of DMEs, mainly as a result of the continuation of lakes' warming which is occurring since the 1980 s worldwide (Piccolroaz et al., 2020) . The ecological effects of such changes in mixing regime are already evident in many deep peri-alpine lakes, such as Lake Garda (Salmaso, 2005; Salmaso et al., 2018). Assessing the occurrence of DMEs based on temperature stratification alone may lead to wrong conclusions in some lakes, because other processes (than surface cooling) affect DMEs (Michalski and Lemmin, 1995). Such processes include density currents due to river inflows and/or differential cooling between littoral and pelagic areas (Meybeck et al., 1991; Peeters et al., 2003; Laborde et al., 2010; Ambrosetti et al., 2010), the contribution of spring snowmelt and duration of ice cover (Flaim et al., 2019; Sadro et al., 2019), storm events inducing thermocline tilting and seiches (Imboden et al., 1987), as well as wind-driven secondary flows inducing up and downwellings at the lake boundaries (Piccolroaz et al., 2019; Reiss et al., 2020). Given all these contributing processes, it is not surprising that there are also lakes where an increase of DMEs has been observed in the last decades. A prominent example is Lake Tovel (northern Italy) where global warming actually increased deep mixing, shifting the mixing regime from meromixis to dimixis (i.e., fully mixing twice per year), due to delayed icing and a longer autumn-mixing period (Flaim et al., 2020). Long-term variability of the wind-stress field can also alter the occurrence of DMEs. A paleolimnological analysis of silicon isotope composition of diatoms in sediment cores of Lake Baikal (Swann et al., 2020) demonstrated that increasing winds caused an enhancement of deep ventilation in the last century. The increase of deep ventilation resulted in larger upwelling of nutrient-rich deep water, which was capable of altering the primary production and community dynamics in the lake.

In this paper, we focus on Lake Garda, the largest lake in Italy, with a surface area of $368 \mathrm{~km}^{2}$ and a volume of $49 \mathrm{~km}^{3}$. Its narrow deep northern trunk is situated in the mountain region of the Alps, while its wide shallow southern part reaches into the Po valley (Fig. 1). Lake Garda is an oligomictic lake, and observations clearly indicate episodic jumps in the bottom water temperature in late winter (cf. Fig. 2), which we refer to as Deep-Cooling Events (DCEs). During such DCEs, the averaged bottom $50 \mathrm{~m}$ temperature in the northern and central part of the lake shows changes of $0.1-0.5^{\circ} \mathrm{C}$ within a $1-2$ week period. Traditionally, the DCEs are associated to DMEs driven by surface cooling through buoyancy-driven turbulence (Salmaso and Decet, 1998). Here, we separate two processes that can lead to DCE due to surface cooling: one is the complete vertical mixing of the lake, and the other is the vertical displacement of a mass of cold and well-oxygenated water from the surface to the bottom

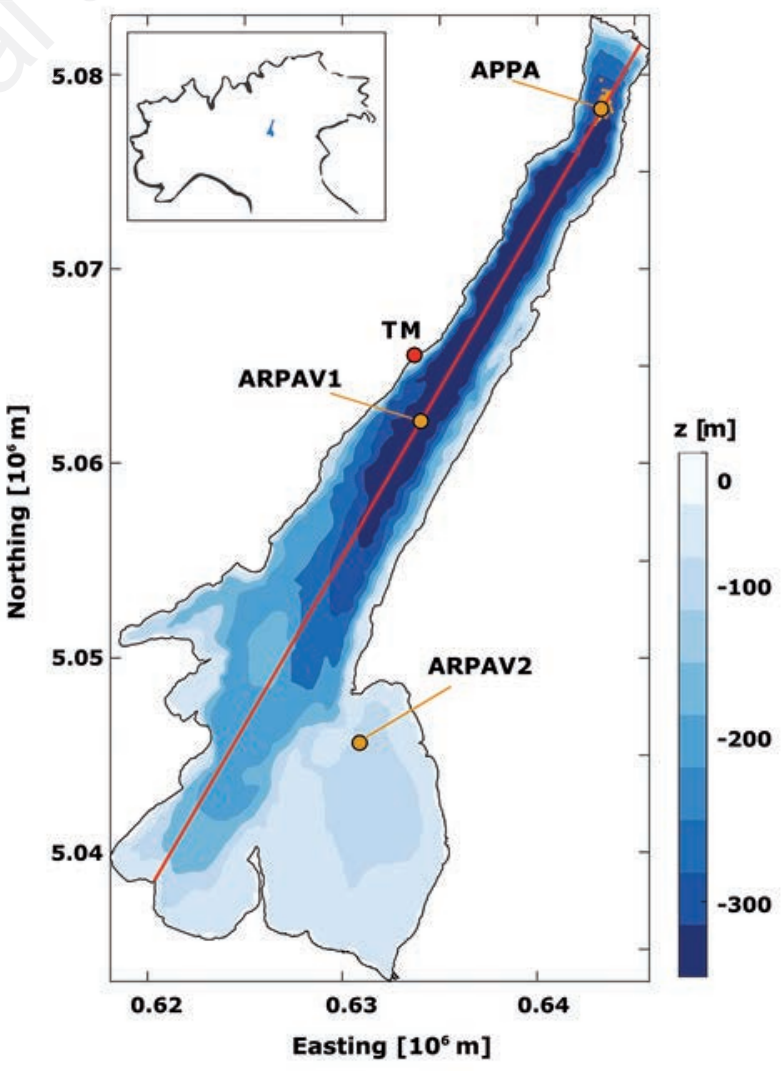

Fig. 1. Map of Lake Garda, including the bathymetry and the locations of the monitoring stations (APPA, ARPAV1/2 and TM). Small yellow dots indicate the locations of $\mu$ CTD samplings near the APPA monitoring point. The deep mooring was deployed close to the ARPAV1 point. Inset: location of Lake Garda in Northern Italy. 
(also termed deep ventilation), without necessarily making the water column uniform.

Lake Garda has recently received considerable attention through new observational and modelling efforts. Piccolroaz et al. (2019) combined in-situ measurements with three-dimensional (3D) hydrodynamic modeling to demonstrate that secondary flows induced by wind stress and affected by Earth's rotation can affect deep mixing in the lake. These findings add a new perspective on DCEs in Lake Garda with respect to previous studies that were mainly performed from an ecological and limnological point of view (Salmaso, 2005; Salmaso et al., 2018).

To understand the physical processes controlling DCEs in Lake Garda, a numerical model (which is fit for purpose for this task) is essential. After a preliminary numerical modeling study by Amadori et al. (2018), Amadori et al. (2021) used observations of water temperature to calibrate a three-dimensional hydrodynamic model (Lesser et al., 2004; Deltares, 2014) for Lake Garda. The analysis of the model's performance to simulate DCEs was based on the comparison with observed temperature time series, but turbulence and velocities were not evaluated. A preliminary description of turbulence-related quantities had been provided by Lenstra et al. (2014), but only for the surface layers in spring. More recently, van Haren et al. (2021) measured turbulence characteristics in the deep waters of Lake Garda to inves- tigate turbulence generation by internal waves. Although providing useful observations, none of these studies explicitly investigated DCEs and their relation to vertical mixing (e.g., DMEs) in Lake Garda. Amadori et al. (2021) mentioned the trend in deep water temperature but did not analyze the processes responsible.

Building on these recent observations and modelling efforts, the goal of the present paper is to improve our understanding of the relation between DMEs and the deep-water temperature (e.g., DCEs) in Lake Garda. Knowledge of this relation is essential to understand how the mixing regime of Lake Garda will change under climate change and gives insight into the interpretation of observations of physical quantities in the lake, e.g. the deep temperature and oxygen record. To investigate these processes, we exploit the existing model by Amadori et al. (2021) to simulate mixing, determine the deep mixing and cooling processes, and finally do a case study where we compare the model data to a measured DCE.

\section{OBSERVATIONAL DATA AND MODEL DESCRIPTION}

\section{Measurements}

From the day of the year (doy) 68 of 2017 until doy 127 of 2018, a team from Utrecht University and the Uni-

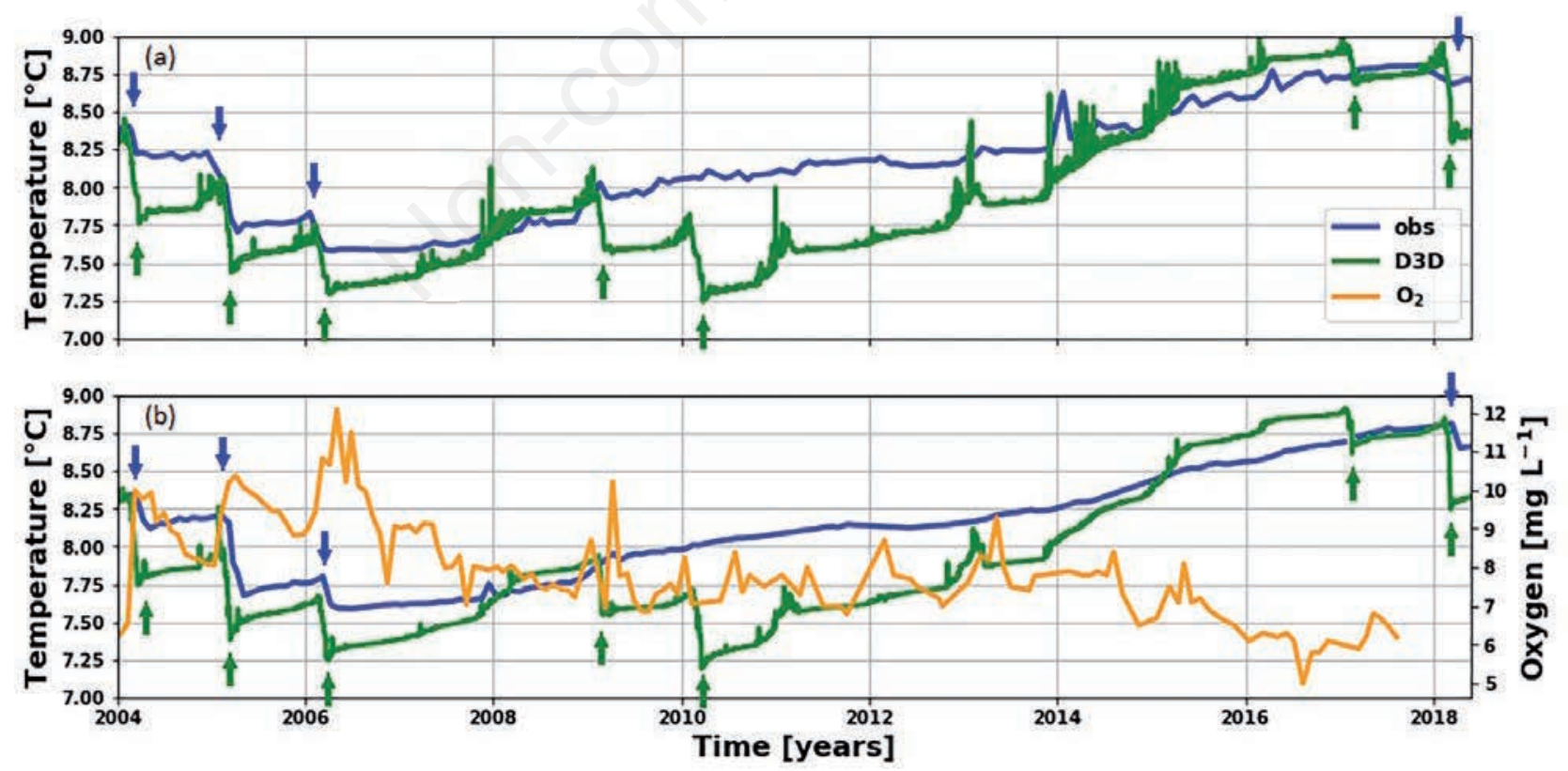

Fig. 2. Lake temperatures averaged over the bottom $50 \mathrm{~m}$ as a function of time at the (a) APPA (depth = 270 m) and (b) ARPAV1 (depth $=344 \mathrm{~m}$ ) location. Oxygen values are also plotted at the ARPAV1 location (orange curve). The blue curves represent the temperature measurements by the APPA and ARPA and the green curves are the Delft3D simulation results. The green arrows indicate where the model simulates DCEs and the blue arrows indicate when these DCEs are observed. 
versity of Trento carried out a joint field campaign on Lake Garda aimed at measuring and characterizing the turbulence in Lake Garda. A microstructure profiler (MicroCTD, by Rockland Scientific International, RSI, Canada; hereafter referred to as $\mu \mathrm{CTD}$ ) equipped with two airfoil shear probes and two fast-response thermistors (FP07) was used on a monthly basis to measure turbulence quantities. The $\mu$ CTD was deployed in free-falling downward profiling mode from the surface to the maximum operation depth of $-100 \mathrm{~m}$. Measurements from the shear probes and the fast-response thermistors were then used to calculate the turbulent kinetic energy (TKE) dissipation rate $(\varepsilon)$. The use of these two different types of sensors allowed to cover the wide range of turbulence conditions occurring in the lake, by taking advantage of their different operational characteristics and accounting for their technical limitations. Specifically, $\varepsilon$ estimates based on the air foil sensors are known to be affected by a noise floor of the order of $10^{-10} \mathrm{~m}^{2} \mathrm{~s}^{-3}$ (Wolk et al., 2002; Fer, 2014; Lincoln et al., 2016). For this reason, the fast-response thermistors were used to cover the range of below this threshold, while shear probes were used to cover the larger values of $\varepsilon$. This allowed to filter out the possible bias introduced by the frequency response correction of fast-response thermistor sensors, which is known to affect estimates in highly energetic environments (Nash et al., 1999; Sommer et al., 2013; Goto et al., 2016; Bluteau et al., 2017). The majority of profiles are taken in the northern narrow part of the lake, and for this application we considered only the measurements taken at the APPA monitoring site 1. Since monitoring data were taken from a boat, the measurements are spread over a region around this point. For more details about these measurements, the reader is referred to Piccolroaz et al. (2019).

From doy 143 of 2017 until doy 150 of 2018, a tautwire sub-surface mooring was deployed at the deepest point (with a depth of $346 \mathrm{~m}$ ) of Lake Garda. The deep mooring measured temperature fluctuations with 100 selfcontained high-resolution temperature sensors. The depth range is $-338 \mathrm{~m}<z<-189.5 \mathrm{~m}$, so there is $1.5 \mathrm{~m}$ distance between the sensors. These high-resolution temperature observations were used to calculate $\varepsilon$. Data after doy 84 of 2018 were not used, as then more than $50 \%$ of the sensors did not work anymore due to battery failure. The noise level of these sensors is less than $0.1 \mathrm{mK}$ and the low-range cutoff of $\varepsilon$ is $10^{-12} \mathrm{~m}^{2} \mathrm{~s}^{-3}$. At the top $(z=-187$ m) of the thermistor chain, a Nortek AquaDopp current meter was mounted, which measured all the three velocity components with an interval of $300 \mathrm{~s}$. For a more detailed description of these measurements, the reader is referred to van Haren et al. (2021).

In addition to the data collected in 2017-2018, vertical profiles of water temperature and oxygen at three loca- tions (APPA, ARPAV1, and ARPAV2 points, see Fig. 1, measured by the corresponding Environmental Protection Agency) were used. These profiles were taken approximately on a monthly frequency and were available for the whole investigated period (2004-2018) and along the entire water column. Finally, data from the meteo station at Toscolano Maderno (Fig. 1), operated by the Regional Agency for Environmental Protection of the Lombardy Region, were taken as representative of the lake weather conditions in the northern trunk.

\section{Hydrodynamic model}

The hydrodynamics in Lake Garda was simulated from 2004 to 2018 using the Delft3D model (Lesser et al., 2004; Deltares, 2014), in the configuration presented in Amadori et al. (2021). The horizontal resolution of the model is about $200 \mathrm{~m}$, and 100 layers in the vertical are used, with a thickness increasing from $1 \mathrm{~m}$ at the surface to 25 meter close to the bottom; the time step is $30 \mathrm{sec}-$ onds. To force the model at the lake-atmosphere boundary, atmospheric fields are taken from a WRF (Weather Research and Forecasting; Skamarock et al. 2008) simulation, whose properties are described in Giovannini et al. (2014) and Amadori et al. (2021). The atmospheric forcing is provided as time and space varying fields of wind velocity, air pressure, air temperature, relative humidity, incoming shortwave radiation and cloudiness. These quantities are available at $2 \mathrm{~km}$ spatial resolution and 1 hour temporal resolution.

The shear stress at the surface $\left(\boldsymbol{\tau}_{s}\right)$ is calculated from the $10 \mathrm{~m}$ wind velocity $\boldsymbol{U}_{10}$ through $\boldsymbol{\tau}_{s}=\rho_{a} C_{d}\left|\boldsymbol{U}_{10}\right| \boldsymbol{U}_{10}$, where the wind-drag coefficient $C_{d}$ is defined via a piecewise linear function of wind speed, consistent with Wüest and Lorke (2003). The surface heat flux is calculated with the Ocean package (Lane, 1989) as $Q_{t o t}=Q_{s n}-Q_{e b}-Q_{e v}$ $-Q_{c o}$, where the four terms in the right hand side are determined by the wind speed, solar radiation, cloudiness, air temperature, air pressure, air humidity and water surface temperature. The heat flux is defined positive when going from the atmosphere to the lake. The meaning of the symbols used in these and in the following equations can be found in Tab. 1.

The TKE $k$ and its dissipation rate $\varepsilon$ are modelled with the $k-\varepsilon$ turbulence model (e.g., Burchard and Baumert, 1995) with the equations:

$$
\frac{\partial k}{\partial t}+\frac{u}{\sqrt{G_{\xi \xi}}} \frac{\partial k}{\partial \xi}+\frac{v}{\sqrt{G_{\eta \eta}}} \frac{\partial k}{\partial \eta}+w \frac{\partial k}{\partial z}-\frac{\partial}{\partial z}\left(D_{k} \frac{\partial k}{\partial z}\right)=P_{k}+B_{k}-\varepsilon,
$$

$$
\frac{\partial \varepsilon}{\partial t}+\frac{u}{\sqrt{G_{\xi \xi}}} \frac{\partial \varepsilon}{\partial \xi}+\frac{v}{\sqrt{G_{\eta \eta}}} \frac{\partial \varepsilon}{\partial \eta}+w \frac{\partial \varepsilon}{\partial z}-\frac{\partial}{\partial z}\left(D_{\varepsilon} \frac{\partial \varepsilon}{\partial z}\right)=P_{\varepsilon}+B_{\varepsilon}-c_{2 \varepsilon} \frac{\varepsilon^{2}}{k}
$$


The equations (1) describe that the evolution of $k$ and $\varepsilon$ is determined by horizontal and vertical advection and vertical diffusion. There are three terms, which can generate or destroy turbulence: production by shear $\left(P_{k}\right.$ and $\left.P_{\varepsilon}\right)$, production (or dissipation) by buoyancy $\left(B_{k}\right.$ and $\left.B_{\varepsilon}\right)$, and loss by dissipation of turbulence ( $\varepsilon$ and $\left.c_{2 \varepsilon} \varepsilon^{2} k^{-1}\right)$. The effect of breaking (surface and internal) waves is not represented in these equations. The production terms are given by the following expressions:

$$
\begin{aligned}
& P_{k}=v_{3 D}\left(\left(\frac{\partial u}{\partial z}\right)^{2}+\left(\frac{\partial v}{\partial z}\right)^{2}\right), \\
& B_{k}=\frac{v_{3 D} g}{\rho \sigma_{\rho}} \frac{\partial \rho}{\partial z} \\
& P_{\varepsilon}=c_{1 \varepsilon} \frac{\varepsilon}{k} P_{k}, \\
& B_{\varepsilon}=c_{1 \varepsilon} \frac{\varepsilon}{k}\left(1-c_{3 \varepsilon}\right) B_{k} .
\end{aligned}
$$

In this formulation, the production of TKE by shear is thus proportional to the square of the vertical shear and the buoyant production of TKE is proportional to the vertical density gradient. In this regard, we recall that Lake Garda is a freshwater lake where the density is almost entirely determined by temperature.
Finally, the vertical (Dirichlet) boundary conditions at top $(z=0)$ and bottom $(z=-H)$ for $k$ and $\varepsilon$ are:

$$
\begin{array}{ll}
\left.k\right|_{z=-H}=\frac{u_{* b}}{\sqrt{c_{\mu}}}, & \left.k\right|_{z=0}=\frac{u_{* s}{ }^{2}}{\sqrt{c_{\mu}}}, \\
\left.\varepsilon\right|_{z=-H}=\frac{u_{* b}{ }^{3}}{\kappa z_{0}}, & \left.\varepsilon\right|_{z=0}=\frac{u_{* s}{ }^{3}}{\kappa \Delta z_{s}} .
\end{array}
$$

At the surface, TKE is proportional to $u_{*_{s}}{ }^{2}=\left|\tau_{s}\right| \rho_{0}$, and hence proportional to the wind-shear stress, while at the bottom it is determined by the square of the bottom friction velocity $u_{* b}$. We refer once again to Tab. 1 for the meaning of the symbols used in these equations and to Amadori et al. (2021) for the parameter values used.

\section{RESULTS}

To motivate the specific time periods over which the

\begin{tabular}{|c|c|c|}
\hline Symbol & Meaning & Dimension \\
\hline$B_{k}, B_{\varepsilon}$ & Production by buoyancy (of $k$ and $\varepsilon$, respectively) & $\mathrm{m}^{2} \mathrm{~s}^{-3}, \mathrm{~m}^{2} \mathrm{~s}^{-4}$ \\
\hline$C_{d}$ & Wind drag coefficient & no dimension \\
\hline$c_{1 \varepsilon}, c_{2 \varepsilon}, c_{3 \varepsilon}$ & Calibration constants $k-\varepsilon$ model & no dimension \\
\hline$D_{k}, D_{\varepsilon}$ & Eddy diffusivity (of $k$ and $\varepsilon$, respectively) & $\mathrm{m}^{2} \mathrm{~s}^{-1}$ \\
\hline$G_{\xi \xi}, G_{\eta \eta}$ & Coefficient used to transform curvilinear to rectangular coordinates & $\mathrm{m}^{2}$ \\
\hline$g$ & Gravitational acceleration & $\mathrm{m} \mathrm{s}^{-2}$ \\
\hline$H$ & Water depth & $\mathrm{m}$ \\
\hline 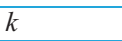 & Turbulent kinetic energy & $\mathrm{m}^{2} \mathrm{~s}^{-2}$ \\
\hline$P_{k}, P_{\varepsilon}$ & Production by shear (of $k$ and $\varepsilon$, respectively) & $\mathrm{m}^{2} \mathrm{~s}^{-3}, \mathrm{~m}^{2} \mathrm{~s}^{-4}$ \\
\hline$Q_{\text {tot }}$ & Net surface heat flux & $\mathrm{W} \mathrm{m}^{-2}$ \\
\hline$Q_{s n}$ & Surface heat flux by solar radiation & $\mathrm{W} \mathrm{m} \mathrm{m}^{-2}$ \\
\hline$Q_{e b}$ & Surface heat flux by net long-wave radiation & $\mathrm{W} \mathrm{m}^{-2}$ \\
\hline$Q_{e v}$ & Surface heat flux by evaporation & $\mathrm{W} \mathrm{m}^{-2}$ \\
\hline$Q_{c o}$ & Surface heat flux by conduction & $\mathrm{W} \mathrm{m^{-2 }}$ \\
\hline$t$ & Time & $\mathrm{s}$ \\
\hline$U_{10}$ & Wind speed (at 10 meter) & $\mathrm{m} \mathrm{s}^{-1}$ \\
\hline$u_{*_{s}}, u_{*_{b}}$ & Friction velocity (at surface and bottom, respectively) & $\mathrm{m} \mathrm{s}^{-1}$ \\
\hline$u, v$ & Horizontal velocity components & $\mathrm{m} \mathrm{s}^{-1}$ \\
\hline$w$ & Vertical velocity component & $\mathrm{m} \mathrm{s}^{-1}$ \\
\hline$z$ & Vertical coordinate & $\mathrm{m}$ \\
\hline$z_{0}$ & Roughness length & $\mathrm{m}$ \\
\hline$\Delta z_{s}$ & Thickness of the surface layer & $\mathrm{m}$ \\
\hline$\varepsilon$ & Turbulent kinetic energy dissipation rate & $\mathrm{m}^{2} \mathrm{~s}^{-3}$ \\
\hline$\kappa$ & Von Kármán constant & no dimension \\
\hline$v_{3 D}$ & Part of eddy viscosity in vertical direction & $\mathrm{m}^{2} \mathrm{~s}^{-1}$ \\
\hline$\xi, \eta$ & Horizontal coordinate & no dimension \\
\hline$\rho$ & Water density & $\mathrm{kg} \mathrm{m}^{-3}$ \\
\hline$\rho_{a}$ & Air density & $\mathrm{kg} \mathrm{m}^{-3}$ \\
\hline$\sigma_{p}$ & Prandtl-Schmidt number & no dimension \\
\hline
\end{tabular}
turbulence characteristics are analyzed, we plot in Fig. 2a (APPA) and b (ARPAV1), the observed bottom temperature and oxygen concentration and the result from the Delft3D simulation over the entire period 2004-2018. This figure shows that the observed bottom temperature slowly rises each year and is sometimes interrupted by episodes

Tab. 1. Meaning of the symbols in the Delft3D model description. 
of strong cooling, akin to DCEs. This happens in 2004, 2005 and 2006, but afterwards these DCEs are absent until 2018, where a small drop in bottom temperature is observed. The trend in bottom temperature at ARPAV1 (Fig. 2b) is anti-correlated with the deep-oxygen concentrations (Rogora et al., 2018), suggesting a link between the drop in temperature and deep mixing. The orange arrows in Fig. 2 indicate the years when DCEs were observed in the measured bottom temperature. Different behavior can be clearly seen by comparing the year 2006 (a year with a DCE) and the year 2015 (no DCE) in late winter. About typically 50-60 days after the beginning of the year, the bottom water temperature drops in 2006, while it rises in 2015. While the model clearly captures the observed DCEs (green curve in Fig. 2), it also simulates false positive DCEs (in 2009, 2010 and in 2017). This model deficiency was already mentioned in Amadori et al. (2021), but no analysis was presented on the misrepresentation of the processes responsible; this will be done in section "Identification of processes controlling deep-water temperature and deep mixing" below.

\section{Turbulence and velocity}

\section{Model results}

In Fig. 3a-b we display TKE dissipation rate in the Delft3D simulation at the ARPAV1 point over the two different years 2006 and 2015. In the summer (doy 160-250) of both years, the largest values of $\varepsilon$ (indicating strong turbulence) occur in the upper $20 \mathrm{~m}$, while during winter (doy 0-90) the entire upper $100 \mathrm{~m}$ experiences strong turbulence. Episodes of strong turbulence reaching larger depths may occur outside winter as well, although rarely, for example on doy 152 of 2006. In winter, episodes of strong turbulence covering the whole depth are observed in 2006, but they are rarer in 2015. Furthermore, strong turbulence is present at the bottom for the entire year.

Turbulence in the $k-\varepsilon$ model can be produced by four processes: shear, buoyancy, bottom friction and wind forcing (see paragraph Observational Data and Model Description). For most of the year, turbulence production by shear $\left(P_{k}\right)$ happens close to the surface and just above the lake floor (Fig. 3 c,d). In winter, turbulence production by shear covers the entire depth in 2006. Production of turbulence by buoyancy $\left(B_{k}>0\right)$ is confined to a narrow surface layer, and only in winter this also happens below 20 $\mathrm{m}$ (Fig. $3 \mathrm{e}, \mathrm{f}$ ). In the rest of the domain, conversion of turbulence to potential energy $\left(B_{k}<0\right)$ dominates (Fig. 3 $\mathrm{g}, \mathrm{h})$. This implies that mixing directly associated with surface cooling is limited to the surface layer during most of the year, and only for short periods in 2006 it affects the whole depth (Fig. 3e).

According to Tab. 2, the average value of $B_{k}$ is negative, even in the surface layer, while that of $P_{k}$ is larger in the surface layer than in the deep layer. The average values of production of turbulence at the boundaries (free surface and bottom) can be estimated from Tab. 2 by assuming steady state and ignoring transport of turbulent quantities in equation (1a). Under these assumptions, the TKE flux at the boundary (bottom or surface) is locally balanced by the net dissipation given by the right-hand side of equation (1a), i.e. $\varepsilon-P_{k}-B_{k}$. According to this simplified estimate, the production of TKE due to the wind (in the surface layer) amounts to $1.48 \times 10^{-8} \mathrm{~m}^{2} \mathrm{~s}^{-3}$ and the production by bottom friction is estimated to be $2.5 \times 10^{-8} \mathrm{~m}^{2} \mathrm{~s}^{-3}$; the latter is hence the major process of TKE production below the surface layer (ignoring the potential influence of wave breaking).

\section{Comparison with $\mu$ CTD}

On doy 50 of 2018 (Fig. 4b), the model simulates $\varepsilon$ relatively well while on doy 256 of 2017 (Fig. 4d) the simulated turbulence is much too strong in the upper $30 \mathrm{~m}$ and much too weak below $30 \mathrm{~m}$. This difference in simulation quality for non-stratified (Fig. 4a) and stratified (Fig. 4c) cases is typical for most times where $\mu \mathrm{CTD}$ measurements are available. The time interval during which the model performs best on simulating $\varepsilon$ is from doy 23-80 of 2018 (not shown), which is the coldest period of the year for Lake Garda. The difference in the profiles of observed and simulated suggests that the amount of turbulence produced near the surface is simulated relatively well, but that the propagation through the vertical is inadequately simulated and leads to weaker turbulence in deeper waters.

The importance of the thermocline becomes clear when looking at Fig. $4 \mathrm{c}$,d. Below the thermocline, turbulence is weaker than above the thermocline due to several reasons. First, the stratification in the thermocline acts as a shield to the vertical transport of turbulence to deeper waters. Second, the horizontal velocities are stronger above the thermocline, so turbulence production by shear is stronger in the epilimnion. Third, internal waves are supported by the stratification, which transport momentum and can induce turbulent overturning. The thermocline simulated by the model is stronger than in the observations in 32 out of the 41 measurements (and in 5

Tab. 2. Average values of different turbulence production terms over time in the Delft3D simulation at the ARPAV1 point. Values are averaged over 14 years of simulation (2004-2018) and winter is excluded (hence values are averaged from doy $90-365$ for every year). All values are in $10^{-9} \mathrm{~m}^{2} \mathrm{~s}^{-3}$.

\begin{tabular}{lccc} 
Depth & $\langle \&\rangle$ & $\left\langle P_{k}\right\rangle$ & $\left\langle B_{k}\right\rangle$ \\
$0-50 \mathrm{~m}$ & 128.6 & 123.6 & -9.8 \\
\hline $50 \mathrm{~m}$ - bottom & 12.5 & 0.8 & -0.6 \\
\hline $200 \mathrm{~m}$ - bottom & 24.8 & 0.05 & -0.25 \\
\hline Total & 29.7 & 19.0 & -2.0 \\
\hline
\end{tabular}




\section{B. Biemond et al.}

of the other 9 cases the thermocline is absent in the upper 100 meter). It follows that a too strong modelled thermocline is a reasonable explanation for the differences between the model and the observations. Indeed, when stratification is practically absent in winter, turbulence is correctly simulated.

A possible reason for the difference in thermocline strength between the simulation and the measurements is that (sub-grid) internal waves are not parameterized in the simulation. Internal-wave breaking at the thermocline can be a source of turbulence (van Haren et al., 1999; Preusse et al., 2010). This will lead to enhanced vertical mixing around the thermocline, thus weakening the vertical temperature gradient, and consequently give a less sharp ther-

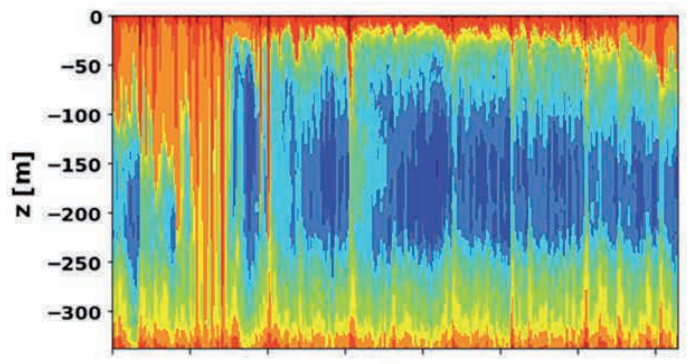

(a)

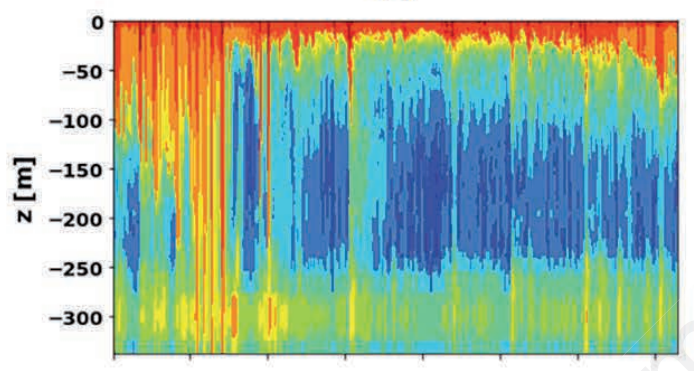

(c)

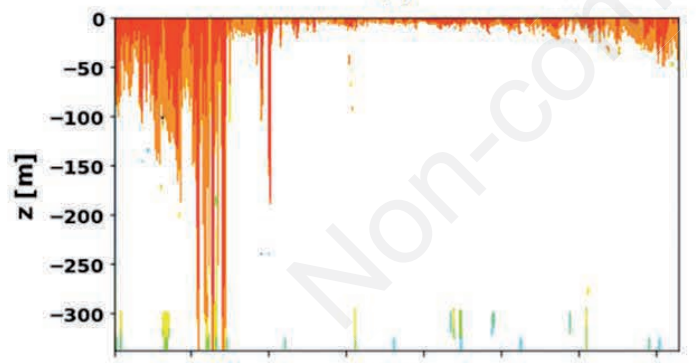

(e)

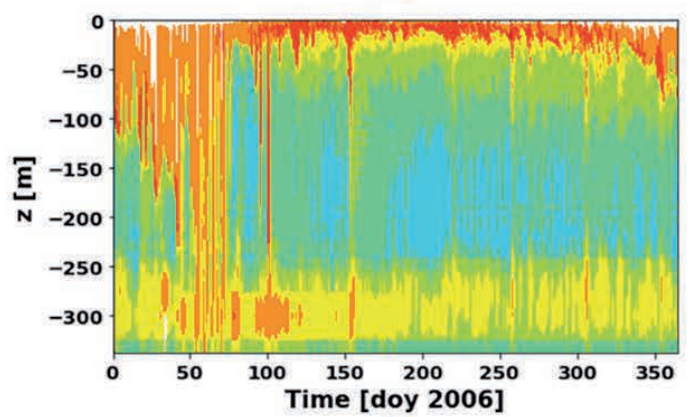

(g)

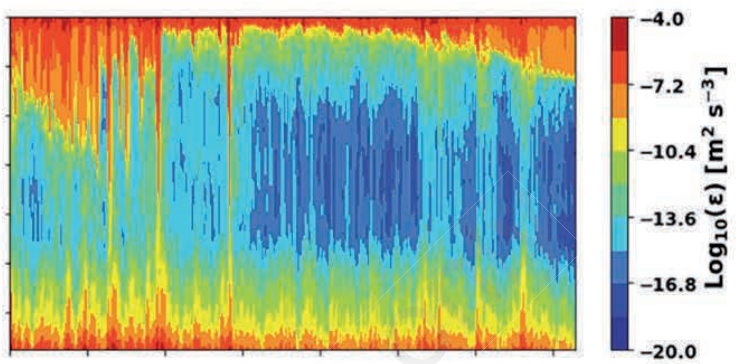

(b)

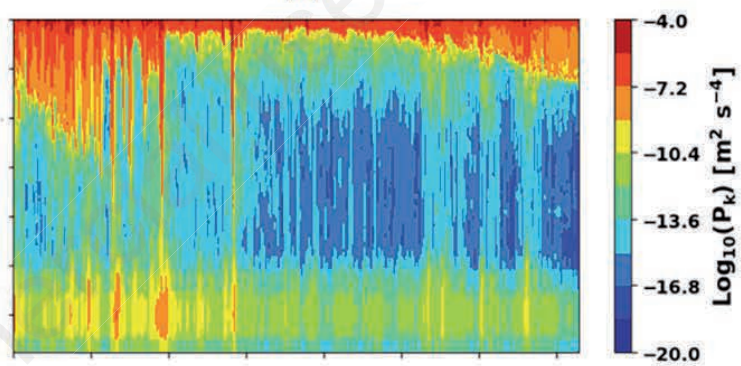

(d)

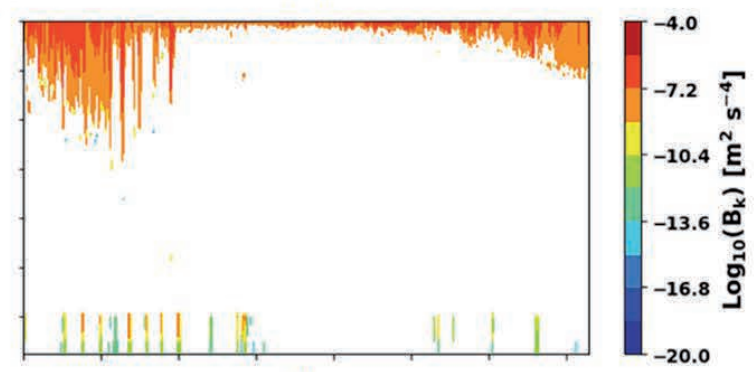

(f)

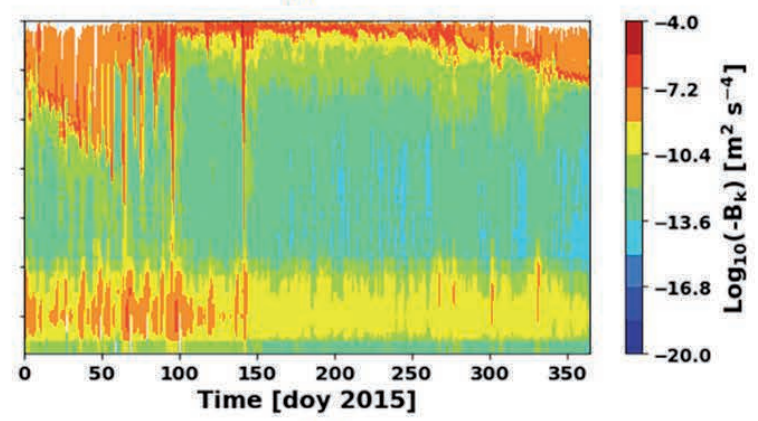

(h)

Fig. 3. Simulated turbulent quantities at the ARPAV1 point versus time and depth. Left subfigures are for 2006 and subfigures at the right are for 2015 (a)-(b) TKE dissipation rate $(\varepsilon)$. (c)-(d) Production of TKE by shear $\left(P_{k}\right)$. (e)-(f) Production of TKE by buoyancy $\left(B_{k}\right) \cdot(\mathrm{g})-(\mathrm{h})$ Conversion of TKE to potential energy $\left(-B_{k}\right)$ in 2006 . White areas are where the value is negative. 
mocline. It should, however, be noted that there are observations where the thermocline strength is adequately simulated, but where $\varepsilon$ is significantly different from observations (not shown). This indicates that the model does have deficiencies to simulate turbulence in the presence of strong vertical temperature gradients, even when the temperature itself is simulated correctly.

\section{Comparison with deep mooring measurements}

Fig. 5a displays measured by the mooring and Fig. 5b displays simulated by Delft3D over the second half of the year 2017. The large white area in Fig. 5a reveals that for a large part of the observed period (72\%), the observed $\varepsilon$ is smaller than the sensor threshold of $10^{-12} \mathrm{~m}^{2} \mathrm{~s}^{-3}$. The $\varepsilon$ values extracted from the model (Fig. 5b) show a situation

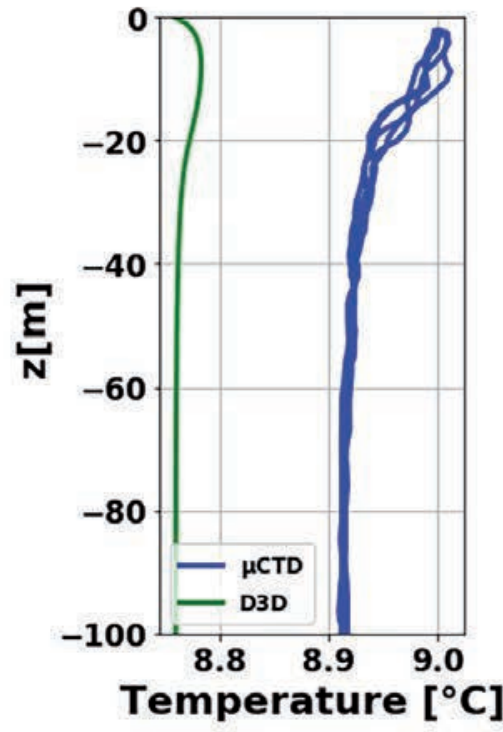

(a)

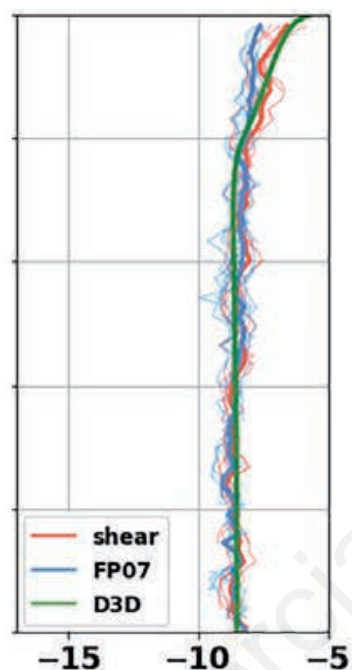

\section{5}

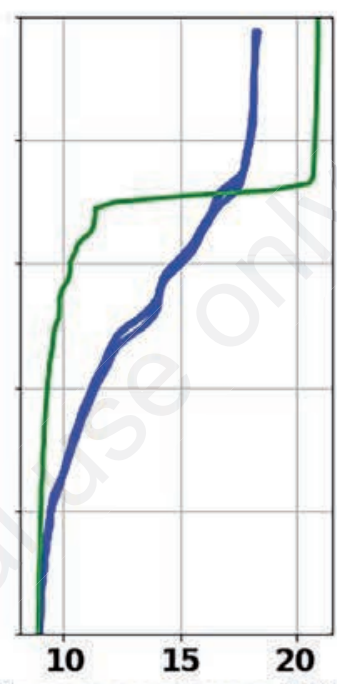

Temperature $\left[{ }^{\circ} \mathrm{C}\right]$

(c)

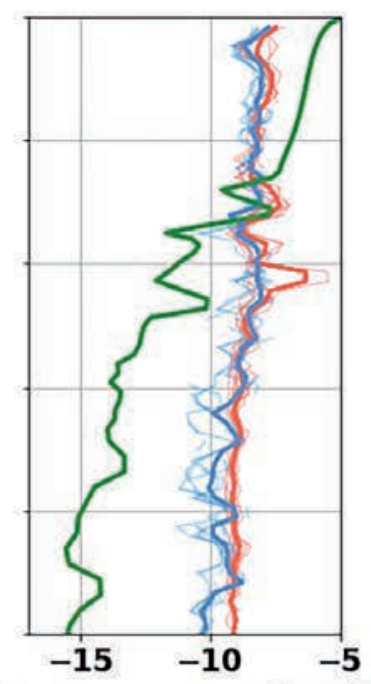

$\log _{10}(\varepsilon)\left[m^{2} s^{-3}\right]$

(b)

(d)

Fig. 4. Temperature and TKE dissipation rate $(\varepsilon)$ versus vertical coordinate as measured by the $\mu$ CTD and simulated by the Delft3D model at the APPA point. (a) Temperature profiles on doy 50 of 2018, 13:30UCT. The dark blue line represents the $\mu$ CTD measurements and the green line is the Delft3D simulation. (b) $\varepsilon$ profiles on doy 50 of 2018, 13:30UCT. The green line is the Delft3D simulation, the blue line are values calculated from the FP07 sensors and the red line are values calculated from shear probes. The shaded lines are individual measurements and the thick line is the average over these measurements. (c,d) As in (a,b), but on doy 256 of 2017, 11:40UTC.

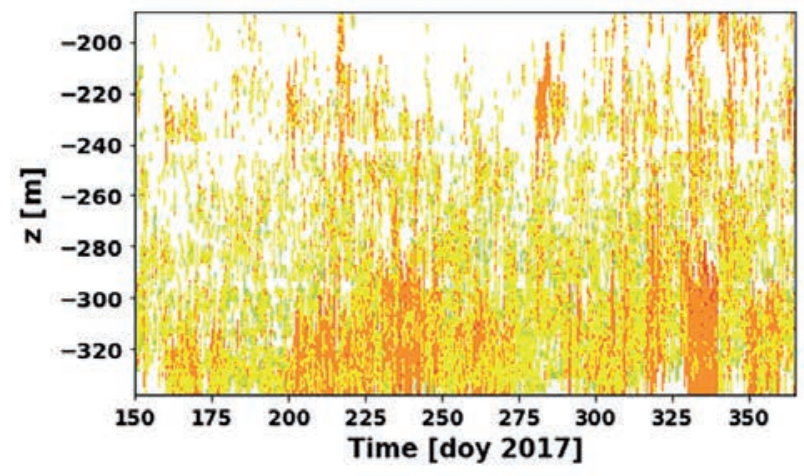

(a)

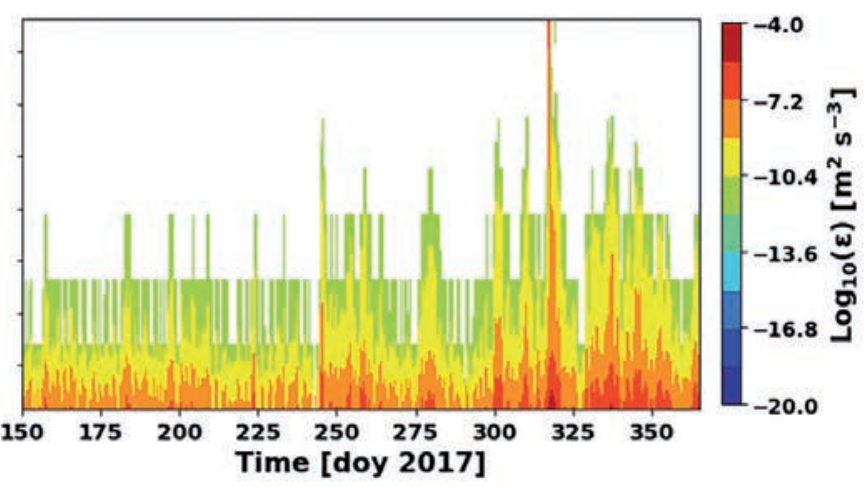

(b)

Fig. 5. TKE dissipation rate $(\varepsilon)$ versus vertical coordinate and time in 2017 at the ARPAV1 point. (a) Mooring measurements. The white area is where in the dataset $\varepsilon=0$, so turbulence is too weak to be measured by the sensors, and is thus below $10^{-12} \mathrm{~m}^{2} \mathrm{~s}^{-3}$ (b) Delft-3D simulation; values of $\varepsilon$ below $10^{-12} \mathrm{~m}^{2} \mathrm{~s}^{-3}$ are also white. 
where $\varepsilon$ has its maximum just above the lake floor, and decays upwards. At several times (doy 240, and from doy 300 to doy 350) stronger turbulence at the bottom is visible, which extends up to $100 \mathrm{~m}$ above the lake floor.

To interpret the reason behind this turbulence maximum, we refer again to the sources of turbulence in the deep lake in the Delft3D simulation (Tab. 2, third row). The net production of turbulence by the sum of shear and buoyancy is negative from the bottom to $200 \mathrm{~m}$. This implies that all the turbulence produced by shear at the bottom (which is the major source) is dissipated in the bottom layer.

The modelled maximum of $\varepsilon$ at the bottom is not found in the observations (Fig. 5a). Thus, while bottom friction should be a negligible source of turbulence in reality, the turbulence dissipation by bottom friction (see equation 3c) is excessive in the model. The reason for this is the vertical size of the grid cells, which is only $25 \mathrm{~m}$ at this depth, which does not allow to reproduce the velocity profile at the bottom and, hence, the velocity in the lower layer is overestimated. On the other hand, the mooring sometimes measures episodes of stronger turbulence (Fig. 5a, for example from doy 330-340 between $280 \mathrm{~m}$ depth and the bottom) that has been identified as breaking internal waves (van Haren et al., 2021). These turbulent episodes are not seen in the simulations because internal waves are not accounted for as a source of turbulence in the model. Moreover, also the vertical grid size is too coarse at this depth to compute internal waves in a sufficiently accurate way.

Velocities are measured at the ARPAV1 point from doy 150 of 2017 until doy 85 of 2018 at a depth of $187 \mathrm{~m}$. The correlation with the velocity values of the Delft3D simulation is small, because it is difficult to properly reproduce the phase of the highly variable velocity field. To gain insight into the performance of the model in simulating the statistics of these velocities, the mean value, standard deviation and skewness of the velocity distributions are listed in Tab. 3 and show the non-Gaussian properties of the velocity field. Both the mean of $u$ and $v$ are approximately zero, which is expected because of the alternating character of the flow. The statistical properties of the simulation agree well with the measurements in the along-channel direction. In the cross-channel direction the variance in the observations is much larger than in the simulations. The reason for this is that the velocities in this direction are weaker and thus more influenced by smaller-scale processes, which are not resolved in the model.

A good agreement between the modelled and observed velocities is found after significant wind events. In Fig. 6, an example of such an event is shown for autumn 2017. Around doy 316, a strong along-channel wind (Fig. 6 a,b) starts to blow, reaching wind velocities of over $20 \mathrm{~m} \mathrm{~s}^{-1}$. The wind excites lake velocities at the depth of the current meter, mostly in the along-channel direction (Fig. 6 c,d). The strength and timing of these velocities is well simulated. After this wind event, an oscillating behavior appears in the observations, which is also reproduced by the model. To investigate whether these velocities can be related to seiches, the periodicity of the currents is investigated. We computed the theoretical period of the seiches in the lake, following the method of Mortimer (1974), and found an oscillation period of 78 hours. Fourier analysis of the modelled and observed velocities reveals that in doy 325-365 of 2017 the dominant period of the oscillation is between 70 and 90 hours, well in agreement with the theoretical result. Since the lake is cooling over the time period shown, vertical density differences will decrease and a longer oscillation period is expected, this behavior is also visible in Fig 6. Hence, the model appears well capable of simulating the basic properties of seiches in the lake, although of course the observational record used for testing is very limited.

\section{Identification of processes controlling deep-water temperature and deep mixing}

Although Delft3D does not simulate all mixing processes correctly, we have seen that the skill of the model, in terms of simulated $\varepsilon$, is better in winter than in other seasons. Since the DCEs happen in winter, we consider the model to be fit for purpose to investigate the relation between DCEs and DMEs.

\section{Bottom warming}

As shown in Fig. 2b, the temperature in the lower 50 $m$ at ARPAV1 in the center of Lake Garda rises slowly throughout the year (with a speed up in autumn and winter). This bottom water warming occurs because the surface water is almost always warmer than the bottom

Tab. 3. Mean, standard deviation and skewness of the horizontal velocity components in the ARPAV1 point. Measurements are by the Nortek AquaDopler meter at 187 meter depth, and for the Delft3D simulation are velocities averaged from 175 to $200 \mathrm{~m}$ depth. The period is doy $150-450$ of 2017.

\begin{tabular}{lccc} 
Quantity & Mean $\left(\mathrm{m} \mathrm{s}^{-1}\right)$ & Standard deviation $\left(\mathrm{m} \mathrm{s}^{-1}\right)$ & Skewness \\
Current meter $u$ & 0.001 & 0.013 & -0.579 \\
\hline Delft-3D simulation $u$ & -0.001 & 0.004 & 0.689 \\
\hline Current meter $v$ & 0.002 & 0.019 & -0.719 \\
\hline Delft-3D simulation $v$ & 0.002 & 0.018 & -0.576 \\
\hline
\end{tabular}


water. The measured warming is relatively slow $\left(0.11 \pm 0.08^{\circ} \mathrm{C}\right.$ per year, values calculated from 2007 2016), since the downward transport of the heat from the surface layer is hampered by the stratification in the water column. This warming rate increases in autumn and win- ter, because the stratification weakens due to surface cooling and vertical mixing increases. In addition, mixing induced by internal waves contributes to this process (van Haren et al., 2021), but such contribution is lacking in the model. The geothermal heat flux in peri-alpine lakes is
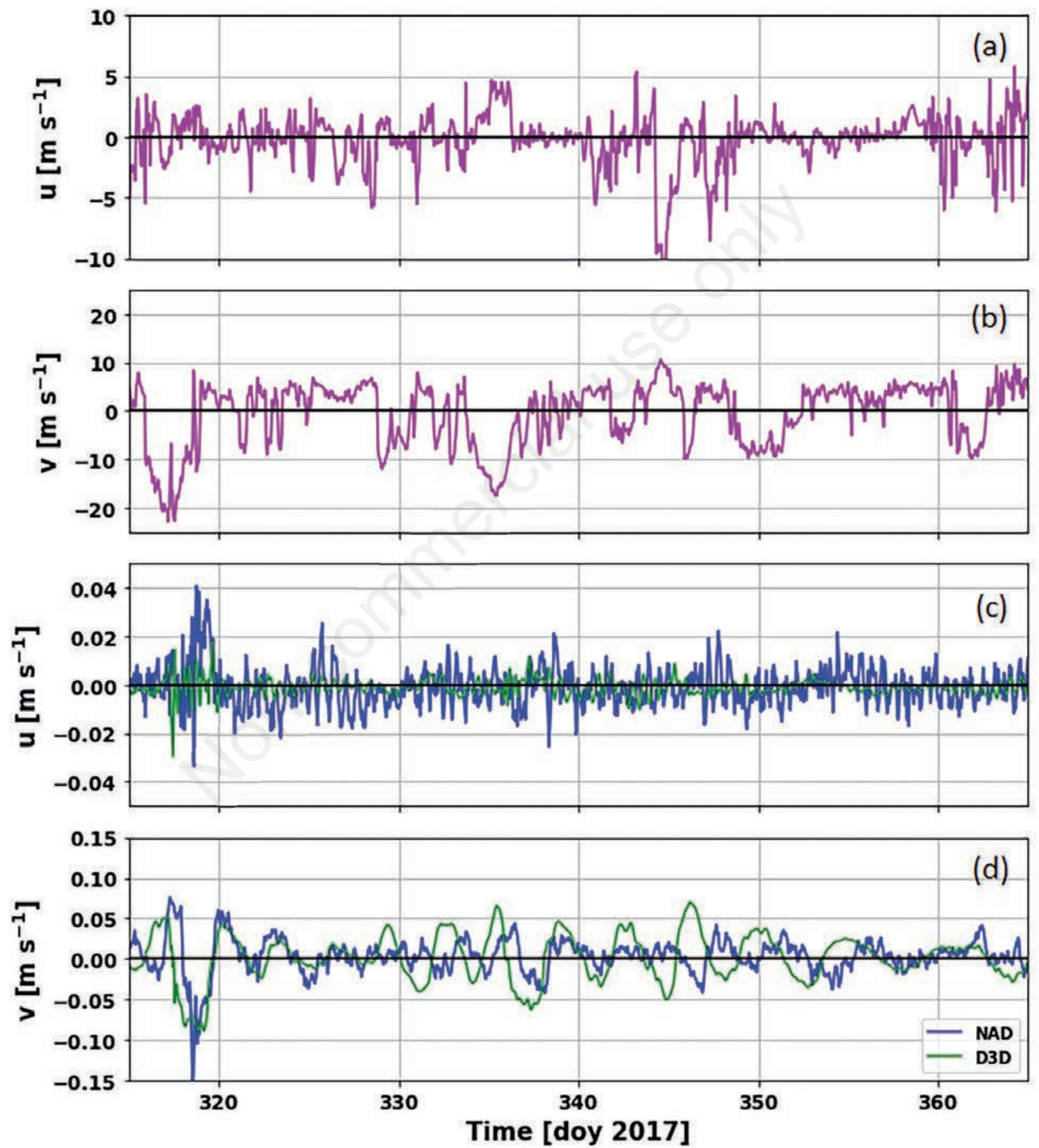

Fig. 6. Velocities and wind speed at the ARPAV1 point versus time. (a) Cross-basin wind velocity. (b) Along-basin wind velocity. (c) Cross-basin velocities versus time. The green line represents velocities simulated by Delft3D, averaged from 175-200 m depth and the blue line are the measurements by the Nortek AquaDopp current meter. (d) As (c), but for the along-basin component. 
found to be $0.12 \mathrm{~W} \mathrm{~m}^{-2}$ (Finckh, 1981), which will lead to additional heating of the deep water; this process was not included in the model. Nonetheless, the bottom water warming in the model is larger than in the measurements, with $0.23 \pm 0.09^{\circ} \mathrm{C}$ per year from 2007 to 2016 , having excluded the years with net bottom water cooling. The major reason for this discrepancy between model and observations is that in winter the epilimnion of the lake in the model is colder than in observations by $0.49 \pm 0.43^{\circ} \mathrm{C}$ (averaged over the upper $50 \mathrm{~m}$ of the lake); as a consequence, the thermal stratification in the model is weaker (as confirmed by the comparison of the measurements at the ARPAV1 point from 2007 to 2017 with the model results) and leads to a larger heat transport from the surface to deeper waters.

\section{Thermocline tilting}

Spikes are visible in the modeled deep water temperature for example from doy 24 to 36 of 2005 (Fig. 2). They can be associated to the action of a strong wind event, through the mechanism of thermocline tilting (Imboden et al., 1987; Socolofsky et al., 1995), as schematically displayed in Fig. 7 a-c. The thermocline tilting process is a phenomenon that only happens when strong winds are present during a specific state of the stratification in the lake. It does not happen when stratification is too weak or absent because then most of the momentum input from the wind will be converted into turbulence. When the momentum input by the wind is relatively low compared to the strength of the thermocline, the vertical stratification will survive the strong winds, because the potential energy barrier is in that case too large for the wind to cause significant horizontal gradients in water temperature. When wind and stratification conditions for the occurrence of thermocline tilting are fulfilled, the development of this wind-driven basin scale flow causes a spike in the deep water temperature signal, because warm water reaches the bottom (Fig. $7 b$ ), but disappears a few days later when the wind weakens and the stratification recovers. The (short-living and local) disappearance of stratification in combination with strong winds causes mixing over the entire water column, giving a DME that homogenizes the temperature and the concentration of chemical components. A further cooling of the surface waters may found favorable conditions to cause a DCE, but this is not always the case. A detailed illustration of this process in a specific event is provided in the Supplementary Material (Section 1).

Unfortunately, direct observational evidence of the thermocline tilting process in winter 2018, when the deep mooring was operational, is not available and the temporal resolution of the monitoring data is not sufficient to capture this process. Note that winds can also generate a cross-lake overturning circulation because of the Coriolis force (Amadori et al., 2018; Piccolroaz et al., 2019). This process differs from the one associated with thermocline tilting where the overturning circulation is along the main axis of the lake and parallel to the wind.

\section{Turbulent cooling}

Another process relevant for determining the deepwater temperature in Lake Garda is indicated here by turbulent cooling and it consists of two well-known processes: convective cooling (Fig. 7 d-f) and shear driven cooling (Fig. 7 g-i). It was identified as a dominant process of deep-water cooling in many other alpine lakes (Ambrosetti et al., 2010).

Convective cooling starts when cold air arrives over the lake (Fig. 7d) which causes a negative surface heat flux and cools the epilimnion. When the epilimnetic water reaches and drops below the temperature of the metalimnetic/hypolimnetic water, the entire water column starts to cool and is also mixed (Fig. 7e), with turbulence produced by negative buoyancy. When the (daily-averaged) surface heat flux becomes positive, a new (weak) thermocline forms (around a typical depth of 10 meter) and the bottom cooling process stops (Fig. 7f). Therefore, the ingredients for the convective cooling process are i) a weak enough stratification, and ii) low air temperatures (typically, values below the deep-water temperature of the lake), producing a negative heat flux at the surface.

Shear-driven cooling starts with a strong wind over the lake (Fig. 7g). Shear-generated turbulence in the epilimnion will erode the thermocline, eventually reaching the bottom (Fig. 7h), and cooling and mixing the entire water column. When the wind weakens and the daily-averaged surface heat flux becomes positive, a new thermocline forms, similar to the previous case (Fig. 7i). The ingredients for shear driven cooling are therefore i) a weak enough stratification, and ii) strong enough winds (typically, values above about $10 \mathrm{~m} \mathrm{~s}^{-1}$ ). These two processes can happen separately or simultaneously. If the air is cold but there is no strong wind, only convective cooling will happen, so the lake will cool but mixing will be relatively weak. If there is a strong wind but no cold air, the lake will mix but cooling will be weak. If the air is cold and there is strong wind, cooling and mixing will both be strong. An example of the combined action of the two processes as simulated by the model is provided in the Supplementary Material (Section 2).

Convective cooling is a well-known mechanism for DCEs (Ambrosetti et al., 2010), also in Lake Garda, and can happen at the end of the winter (February and March) when the lake surface temperature is at its lowest. Temperature profiles measured at the APPA point during the DCE in the winter of 2004 (not shown) indicate that the coldest water was at the surface, hence negative buoyancy was present, and turbulent cooling was taking place. Such a situation was not observed, for example, in 2008 (no DCE), although this does not necessarily mean that tur- 
bulent cooling did not happen at all during that winter as this process is episodic and the observed profiles were taken on a monthly basis.

\section{Differential cooling}

The deep water of Lake Garda can also cool because of a process called differential cooling, as schematically shown in Fig. $7 \mathrm{j}-1$.
This process is closely connected to turbulent cooling happening in different parts of the lake. Differential cooling was also observed in other lakes and has been discussed extensively in the literature (Fer et al., 2002; Peeters et al., 2003; Ambrosetti et al., 2010; Verburg et al., 2011).

A turbulent cooling event is present in the simulation in the winter of 2005 (doy 64) and the details are described in the Supplementary Material (Section 3). Here,

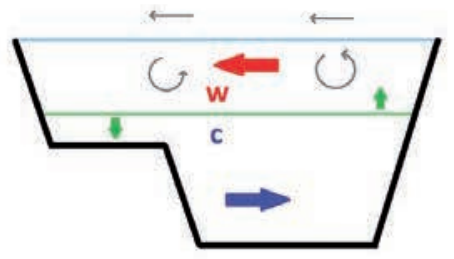

(a)

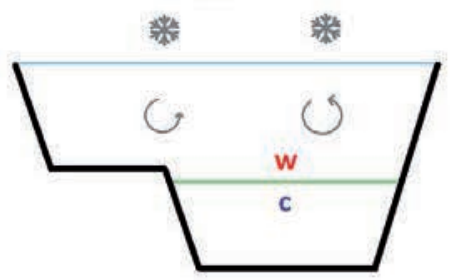

(d)

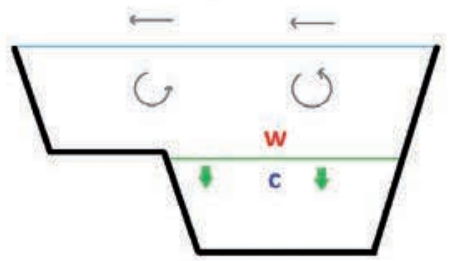

(g)

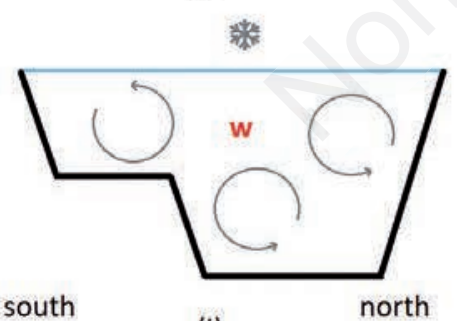

(j)

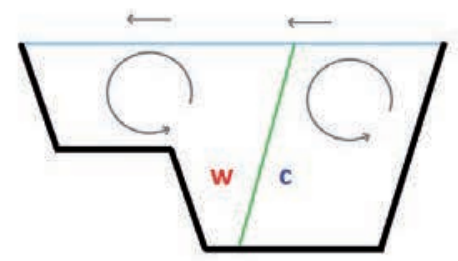

(b)

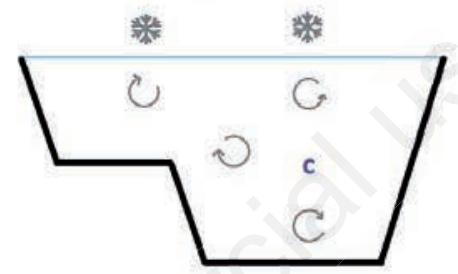

(e)

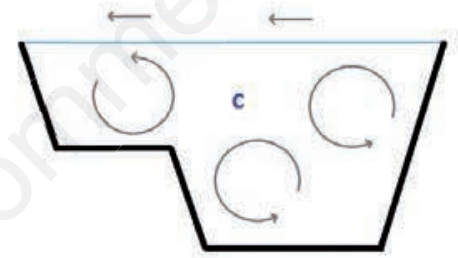

(h)

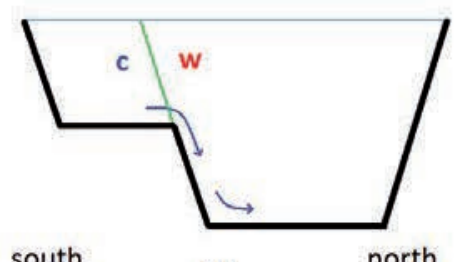

(k)

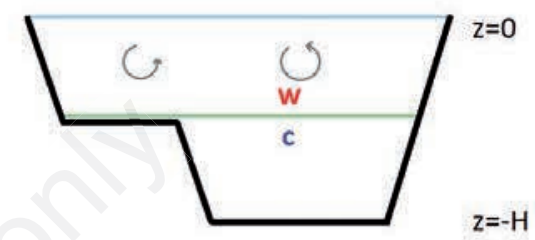

(c)

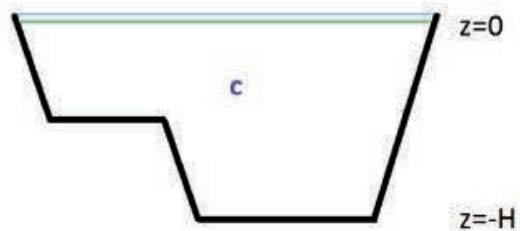

(f)

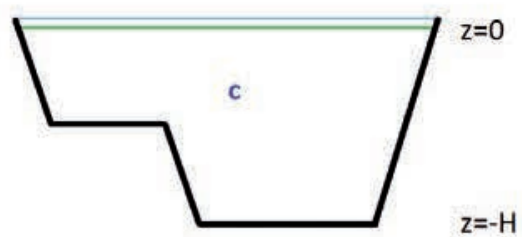

(i)

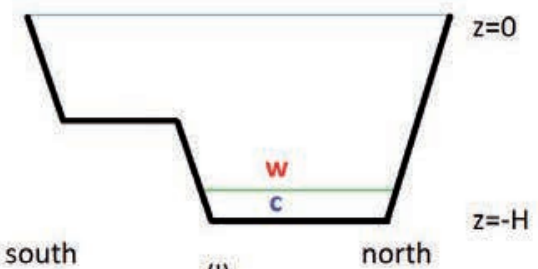

(I)

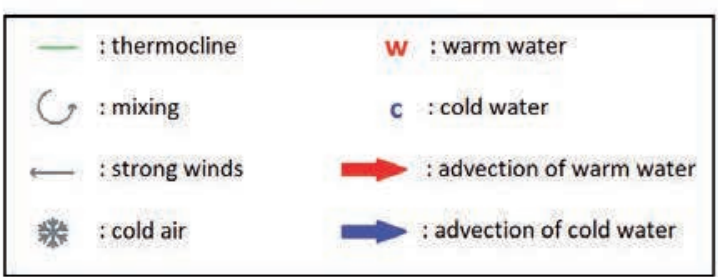

Fig. 7. Schematic overview of the different deep cooling mechanisms in Lake Garda. The meaning of the symbols used is indicated in the legend. Figures are chronologically orderered from left to right. Subfigures (a)-(c) indicate thermocline tilting, (d)-(f) display the convective part of turbulent cooling, (g)-(i) display the shear driven part of turbulent cooling and finally (j)-(1) display the advective effects after differential cooling. 
we summarize the main dynamics. Initially, the whole lake is cooling over the entire water column (Fig. 7j), but with a volume of colder water at the bottom in the southern part. When turbulent cooling ceases, colder water starts to appear at the bottom of the central, deep part of the lake. This cold water cannot be created by turbulent cooling at that location, since the surface water never was this cold. Instead, the origin of the cold water is advection of water from the shallower parts of the lake, through bottom currents (Fig. 7k). This is confirmed by the currents in the model, where a northward current is present close to the bottom and the spread of the cold water matches with the along-channel bottom flow velocities. The flow simulated during these events (not shown) is independent of wind speed and direction at that time, and differential cooling happens even when the wind is very weak. The northward bottom currents are caused by density differences: cold water from the south flows to the deep northern part because of its larger density. The simulation shows that it takes approximately one week to reach the north. In this way, differential cooling generates stratification in the deep part of the lake because cold water flows beneath warm water (Fig. 71).

A confirmation of the existence of differential cooling in Lake Garda comes from the analysis of bottom temperature at the (shallow) ARPAV2 point and at the (deep) ARPAV1 point (Supplementary Material, Section 3): the temperature profile at the ARPAV1 point shows that, just above the bottom, cold water is present over a small depth range. Differential cooling could also be generated by cold water from the shallower east or west sides of the basin. However, no significant contributions by this process are found in the model. This is expected because the horizontal temperature gradients are very weak over the northern part of the lake in winter. Differential cooling also results in a weak stratification at the bottom, which is quite different from the one due to turbulent cooling. This signature could be used to distinguish future DCEs, as it should be visible in temperature time series at different depths.

\section{Case study: the 2018 DME}

Having identified the dominant processes responsible for the DCEs in Delft3D simulations, we now take winter 2018 as a case study when a DCE was measured (in February 2018) by the deep mooring (van Haren et al., 2021). This provides the most detailed observational data of bottom water cooling in Lake Garda so far. Below, this event is studied and the processes responsible are identified.

Plots of wind speed, surface heat flux and air temperature (from the WRF simulation and measurements) are shown in Fig. 8. The highest wind speeds are observed around doy 53. However, this does not lead to a very low surface heat flux. Around doy 55, the air temperature drops about $10^{\circ} \mathrm{C}$, associated with the arrival of a Siberian front. This leads to a negative surface heat flux, but because the wind was not strong at this moment, the heat flux did not become (Fig. 8b) strongly negative as, for example, for the case of turbulent cooling examined in the Supplementary Material (Fig. S2). The simulated air temperature is mostly in line with the measurements, except that the drop in air temperature due to the Siberian front was more intense in the simulation. Moreover, wind velocities are lower in the measurements, in particular from doy 50-55. We note that the observations are taken at the Toscolano Maderno weather station (Fig. 1), which is on the land, while the ARPAV1 point is in the middle of the lake, where the wind is not hindered by obstacles. Based on a comparison between on- and off-shore wind velocity

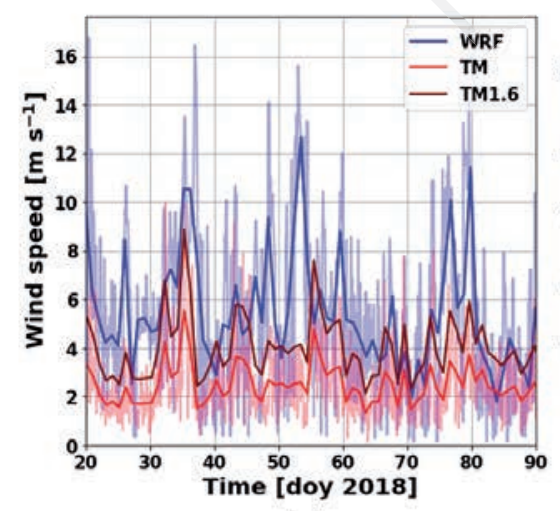

(a)

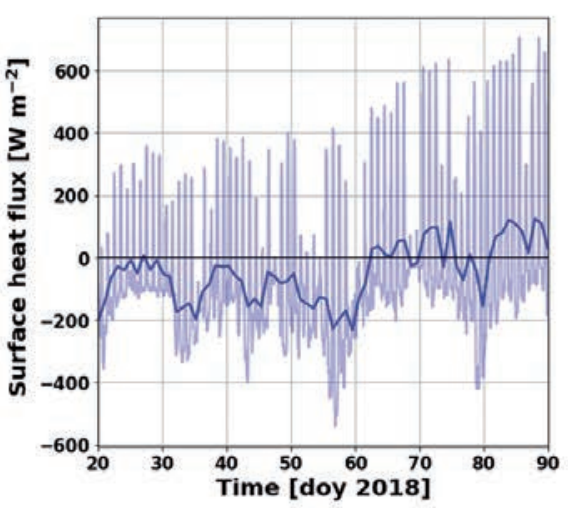

(b)

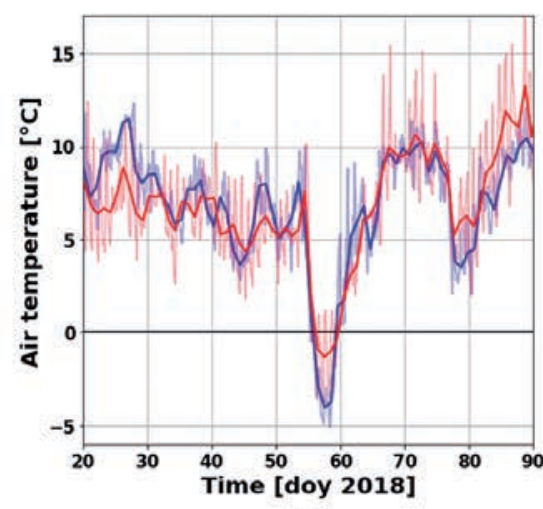

(c)

Fig. 8. Atmospheric forcing versus time at the ARPAV1 point. The thick line represents the daily averages, while the shaded line shows the hourly values. Data from the WRF (wind and air temperature) and Delft3D (surface heat flux) simulation (blue) and from measurements at the TM (Fig. 1) station (red). The brown line is the measured wind speed times 1.6, which is more representative for the wind speed above the lake (Piccolroaz et al., 2019). (a) Wind speed. (b) Surface heat flux. (c) Air temperature. 
measurements, Piccolroaz et al. (2019) estimated a factor 1.6 between the two but this was for a meteorological station in the north-western shore (Limone del Garda) and the APPA off-shore site. Hence, this factor may be larger between the Toscolano-Maderno and ARPVA1 station. The agreement between observed and simulated wind is

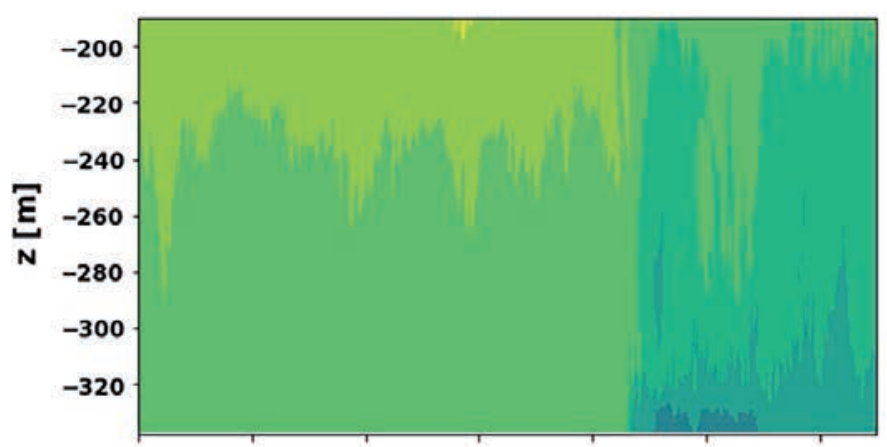

(a)

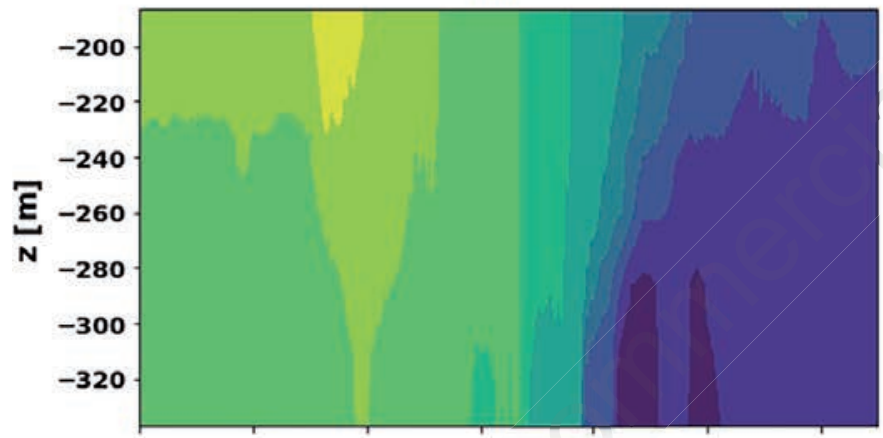

(c)

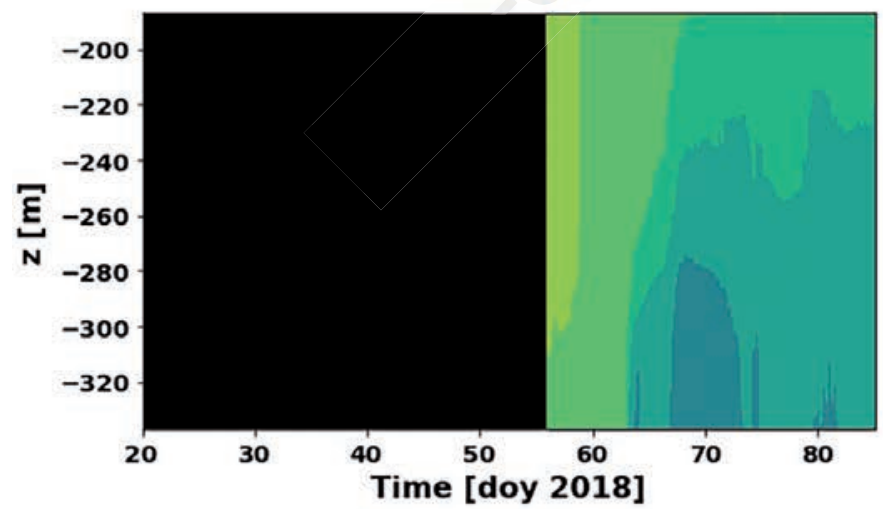

(e)

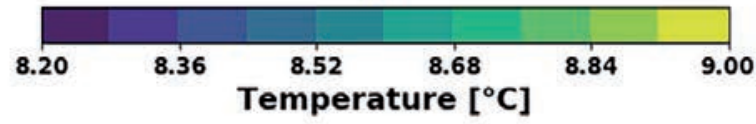

reasonable in the investigated period with the exception of doys 50-55 and 75-80, when the simulated wind speed is clearly an overestimation.

The measured vertical distribution of temperature (Fig. 9a) shows that the water column is nearly homogeneous around doy 62, when a sudden cooling occurs (a

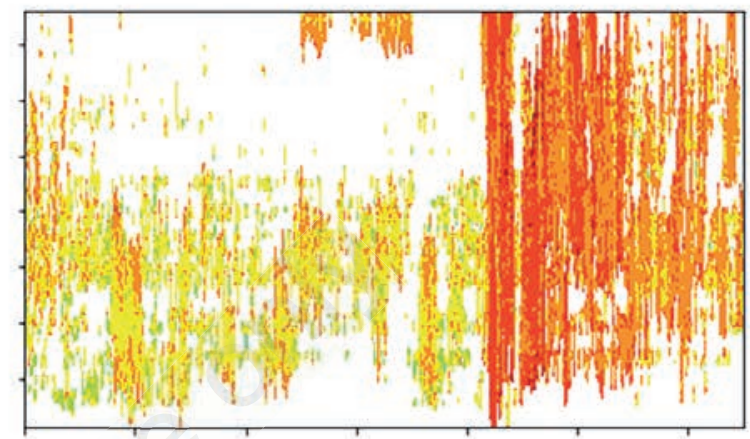

(b)

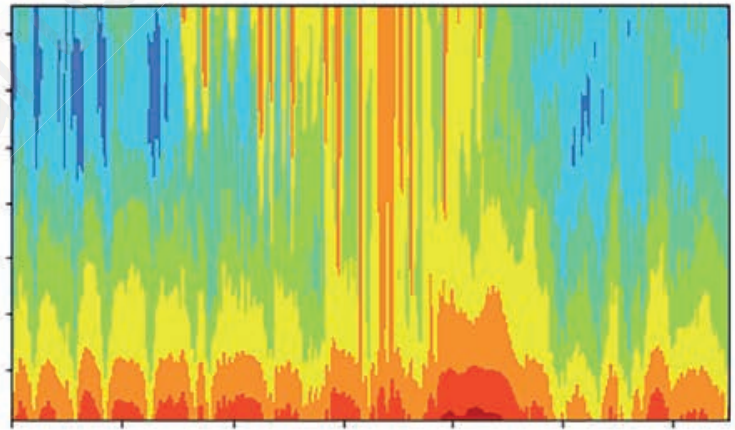

(d)

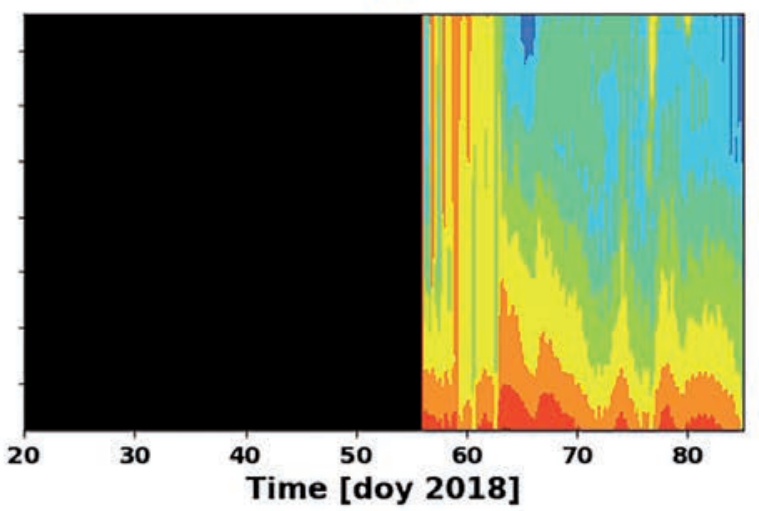

(f)

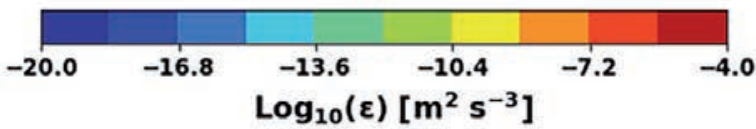

Fig. 9. Observed and simulated quantities at the ARPAV1 point versus time and vertical coordinate in winter 2018. (a) Temperature measured at the mooring. (b) TKE dissipation rate $(\varepsilon)$ calculated from measurements at the mooring. (c) Temperature simulated by Delft3D. (d) simulated by Delft3D. (e) Temperature simulated in a different run (described in text) of Delft3D. (f) $\varepsilon$ simulated in the additional simulation (described in the text) of Delft3D. 
DCE). This cooling is most pronounced at the bottom. Also Fig. 9b indicates strong turbulence remains present for a few weeks after doy 62 . According to the description of the different cooling mechanisms, differential cooling is the best candidate to explain the observations. The timing of bottom water cooling is what one would expect if this process were happening. Cold air temperatures arrive over the lake around doy 55 (cooling the entire lake, also the shallow southern part), and about a week later the first cooling is observed at the ARPAV1 point, in line with the propagation velocity of the cold water in the model (see paragraph Differential Cooling). The fact that the minimum water temperature occurs at the bottom is also consistent with differential cooling. In van Haren et al. (2021), it is also stated that this DCE is due to differential cooling, but they suggest that the cold water comes from the north, based on the flow direction observed by the current meter: strong south-westward horizontal velocities are observed by the Nortek AquaDopp current meter during this event. However, according to the model results and the measurements of temperature, the biggest temperature drop is only present in the bottom layer (with a maximum vertical extent of $50 \mathrm{~m}$ ). This makes it unlikely that the current meter (150 meter above the bottom) measures the flow which transports this cold water, but rather measures a counter-current. If at the bottom a northward flow (deflected to the right, i.e. east, by the Earth's rotation) exists, a southward (again deflected to the right, i.e. west) counter- current above is expected.

In the simulation, stronger turbulence is present during the differential cooling process, but it remains close to the bottom and is for a large part generated by the model through bottom friction. In the observations, turbulence peaks over most of the depth range of the mooring during that time. In Fig. 9c, the simulated water temperatures also do not show a good agreement with measurements during this event. In particular, between doy 45 and 65 several episodes of turbulent cooling are present in the Delft3D simulation and the strong wind at doy 53 seems to be the major cause of this. Fig. 10 shows that the Siberian front (doy 55-60) caused most bottom cooling in the southern part of the lake. This water flows with approximately 0.07 $\mathrm{m} \mathrm{s}^{-1}$ to the north (according to Fig. 10), which is in agreement with the bottom velocities in the simulation (not shown).

Delft3D is not able to simulate the correct amount of bottom water cooling and mixing in winter 2018. This disagreement originates from the stronger (model) winds from doy 50-55 and the fact that the surface layer is colder in the simulation than in reality. A $\mu$ CTD measurement at doy 59 at the APPA point indicates that the surface layer is $0.2^{\circ} \mathrm{C}$ colder in the simulation than in observations, partly caused by overestimation of the wind speed from doy 50-56. This explains why the Delft3D simulation sim- ulates turbulent cooling at the ARPAV1 point which does not (or barely) happen in reality.

To better understand what causes the model's inaccuracy during the cooling event in February 2018, an additional simulation was performed. The model was restarted from doy 40 of 2018, but now integrated with the forcing from doy 56 to 85 . The motivation for this simulation was that the state of the lake as simulated on doy 40 well describes the observed lake conditions. The bottom temperature is well simulated on doy 40 by the model (the root mean squared error is $0.037^{\circ} \mathrm{C}$ in the overlapping depth range with the mooring). Furthermore, this temperature is very similar to that observed on doy 56 (the average temperature in the depth range of the measurements is $8.84^{\circ} \mathrm{C}$ at doy 40 and $8.83^{\circ} \mathrm{C}$ at doy 56). At the same time, the simulated surface temperature on doy 40 is consistent with the closest (in time) $\mu \mathrm{CTD}$ temperature profile, available on doy 51 (the root mean squared error is $0.16^{\circ} \mathrm{C}$ ). Results of the additional simulation are displayed in Fig. 9 e,f. The bottom water cooling is now solely caused by advection, which starts at doy 63 , just as in the observations. The mixing observed at doy 59-62 is caused by negative buoyancy from the surface, but causes hardly any bottom water cooling. These new results strengthen the confidence in the capabilities of Delft3D to model

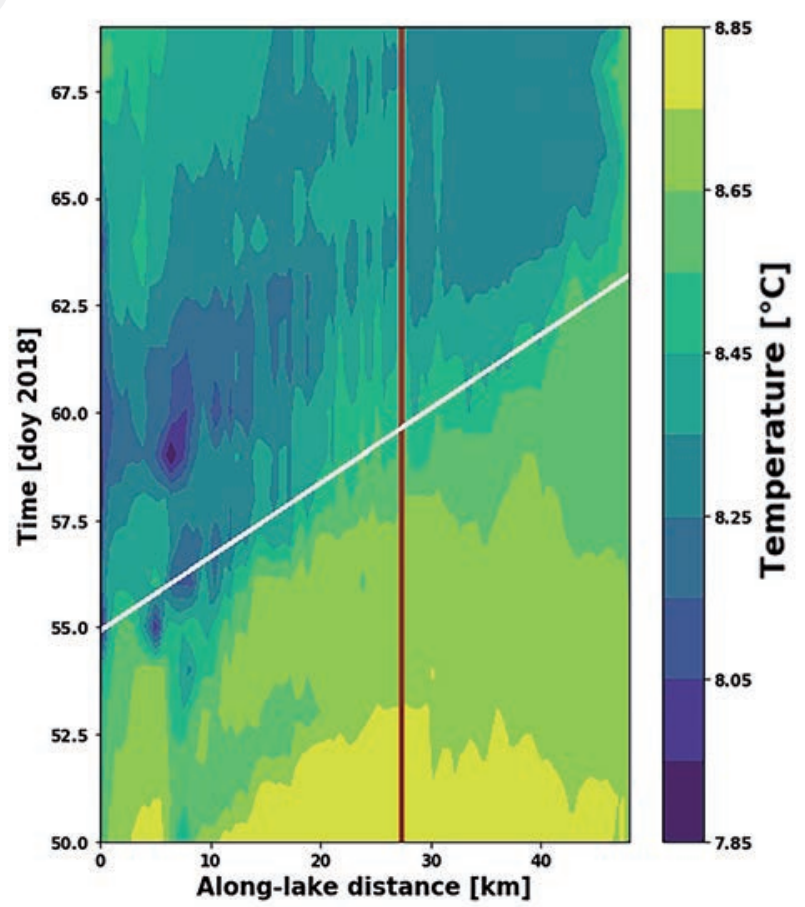

Fig. 10. Simulated temperature averaged over the bottom $50 \mathrm{~m}$ of the lake versus along-lake distance (south-north) and time in winter 2018. The vertical brown line is the location of the ARPAV1 point and the white line indicates the $0.07 \mathrm{~m} \mathrm{~s}^{-1}$ alongbasin velocity. 
DMEs and DCEs and emphasizes the importance of forcing the model with correct wind speeds.

\section{DISCUSSION}

The results show that the model is able to simulate turbulence in Lake Garda in a reasonable way. However, once stratification appears, the TKE dissipation rate in the hypolimnion is smaller in the simulation than in observations. This is likely caused by an overestimation of the thermocline strength in the simulation and/or by the absence of the contribution of breaking internal waves, which could also explain why the thermocline is stronger in the simulation. At the bottom, turbulence is artificially generated by bottom friction in the simulation. So to improve the simulation of turbulence in Delft3D, internal waves should be included and the vertical grid size of the model next to the bottom should be made finer. We have seen that in Lake Garda, DCEs can occur with and without a DME happening simultaneously, e.g. turbulent cooling causes a DCE and DME, while differential cooling only cools the bottom water and thermocline tilting only mixes the lake. Thus, we propose specific features of the two processes. On the one hand, DCEs are an alteration of deep water temperature which can be caused by several factors. Cold water can be transported downwards either by convective transport from the surface or by deep downwelling from littoral zones or conterminous sub-basins. These mechanisms do not necessarily produce a complete mixing of the lake. Indeed, localized downwellings may also cause the opposite, as deep cooling enhances the thermal gradients in the deepest layers. On the other hand, in order to clearly identify and understand the occurrence of a DME, we need to observe the vertical distribution of all water quality components (temperature, oxygen, salinity, nutrients concentration), as well as turbulent quantities. Based on the numerical results, we have seen that DMEs can occur due to thermocline tilting and turbulent cooling, but among the two processes, only the latter is also associated with DCE (because it is mainly driven by a surface cooling). However, mixing produced by tilting can favor the occurrence of a subsequent DCE in the presence of a surface cooling over a homothermal water column.

The model clearly captures DCEs (green arrows in Fig. 2) and shows that turbulent cooling and differential cooling can lead to a series of cooling events in a cold winter. These take place approximately from the moment that the thermocline disappears, for example after a strong wind event, until the daily averaged surface heat flux remains positive and spring starts. The use of the hydrodynamic model and the observations of the deep mooring were essential to find that these DCEs occur in series, while such information could not have been deduced from the low-frequency monitoring data. Thus we showed how hydrodynamic models can be used to fill in gaps arising by low-frequency monitoring data in lakes.

With this knowledge of the processes in Lake Garda, we can now understand the observed temperature and oxygen profiles better (Fig. 2): In 2004, 2005 and 2006 a series of cooling and mixing events occurred, in 2018 a single cooling event occurred and in 2009 probably thermocline tilting happened: oxygen-rich surface water reached the bottom but disappeared shortly afterwards. The Delft3D model simulates false positive DCEs (in 2009, 2010 and in 2017), where a drop in deep water temperature is simulated but not observed. Amadori et al. (2021) ascribed this model inaccuracy to a misrepresentation of the atmospheric forcing provided by the atmospheric model in these periods, i.e. an overestimation of wind speed and an underestimation of air temperature during winter periods, which led to a cold bias in the upper layer temperature. The latter indeed makes DCEs more likely to happen, since a prerequisite for this is weak enough stratification. Also, salinity is ignored in the simulation, which will in reality often stabilize the water column (although not always, see Fig. 2 in van Haren et al., 2021). Salinity contributes about $15 \%$ to density variations that are thus dominated by temperature variations in the deeper half of Lake Garda.

The effect of climate change on the frequency of DMEs in Lake Garda has been already investigated by Salmaso et al. (2018), who showed how the thermal stratification is strengthened by warming air temperatures, thus making DMEs less frequent. However, since the bottom water temperature increases during the periods without DMEs in Lake Garda (up to $1^{\circ} \mathrm{C}$ per decade), the temperature difference between surface and bottom waters does not necessarily increase under higher air temperatures. Based on the results provided here, the probability for a DME to happen is more sensitive to the frequency and strength of strong wind events during (relatively cold) winters, because these events are the direct drivers of mixing processes. How their characteristics change above Lake Garda is an issue that should be addressed by high-resolution climate-model based projections of future atmospheric forcing over the lake. Even when those forcing fields are available, the use of a thermo-hydrodynamic model to provide reliable projections of future DMEs is challenging. Further efforts combining modeling and observations are necessary to address this issue.

\section{CONCLUSIONS}

In this study, the relation between deep-mixing events (DMEs) and deep-cooling events (DCEs) in Lake Garda was investigated using observations and a long 2004 2018 simulation with a three-dimensional hydrodynamic 
model (Delft3D forced by the atmospheric model WRF). Comparing observations with the simulations revealed that the values of the turbulent kinetic energy dissipation rate close to the surface and in winter are reasonably well simulated. Two processes, thermocline tilting and turbulent cooling, were identified which can cause DMEs in Lake Garda. Turbulent cooling causes a simultaneous occurrence of a DME and a DCE. A DCE can also occur due to differential cooling. We showed that differential cooling was the best explanation for the DCE in the winter of 2018, where both measurements of temperature and turbulence are available.

\section{ACKNOWLEDGEMENTS}

The Delft3D simulations were carried out on the Cartesius supercomputer at SURFsara (www.surfsara.nl). We thank Michael Kliphuis (IMAU-UU) for his help with these simulations and Lorenzo Giovannini for the WRF simulations. Part of this work was supported by the EU Horizon 2020 programme through the EOMORES project [grant number 730066]. Data (post-processing Python codes plus relevant simulation results) are available on https://git.science.uu.nl/w.t.biemond/master-thesis-lake-garda.

\section{REFERENCES}

Amadori M, Piccolroaz S, Giovannini L, Zardi D, Toffolon M, 2018. Wind variability and Earth's rotation as drivers of transport in a deep, elongated subalpine lake: The case of Lake Garda. J. Limnol. 77:1814.

Amadori M, Giovannini L, Toffolon M, Piccolroaz S, Zardi D, Bresciani M, Giardino C, Luciani G, Kliphuis M, van Haren H, Dijkstra HA, 2021. Multi-scale validation of a 3D atmosphere-lake model based on standard monitoring data. Environ. Modell. Softw. 139:1364-8152.

Ambrosetti W, Barbanti L, Carrara E, 2010. Mechanisms of hypolimnion erosion in a deep lake (Lago Maggiore, N. Italy). J. Limnol. 69:3-14.

Bluteau C, Lueck R, Ivey G, Jones N, Book J, Rice A, 2017. Determining mixing rates from concurrent temperature and velocity measurements. J. Atm. Ocean. Technol. 34:2283- 2293.

Burchard H, Baumert, H, 1995. On the performance of a mixedlayer model based on the $\kappa-\varepsilon$ turbulence closure. J. Geophys. Res.-Oceans 100:8523-8540.

Crawford GB, Collier RW, 1997. Observations of a deep-mixing event in Crater Lake, Oregon. Limnol. Oceanogr. 42:299-306.

Deltares, 2014. Delft3D-FLOW user manual. Delft, the Netherlands.

Fenocchi A, Rogora M, Sibilla S, Ciampittiello M, Dresti C, 2018. Forecasting the evolution in the mixing regime of a deep subalpine lake under climate change scenarios through numerical modelling (Lake Maggiore, Northern Italy/Southern Switzerland). Clim. Dynam. 51:3521-3536.

Fer I, 2014. Near-inertial mixing in the central arctic ocean. J. Phys. Oceanogr. 44:2031-2049.
Fer I, Lemmin U, Thorpe SA, 2002. Winter cascading of cold water in Lake Geneva. JGeophys. Res.-Oceans 107: 13-16.

Finckh P, 1981. Heat-flow measurements in 17 perialpine lakes: Summary. GSA Bull. 92:108-111.

Flaim G, Nishri A, Camin F, Corradini S, Obertegger U, 2019. Shift from nival to pluvial recharge of an aquifer-fed lake increases water temperature. Inland Wat. 9:261-274.

Flaim G, Andreis D, Piccolroaz S, Obertegger U, 2020. Ice cover and extreme events determine dissolved oxygen in a placid mountain lake. Water Resour. Res. 56: e2020WR027321.

Giovannini L, Antonacci G, Zardi D, Laiti L, Panziera L, 2014. Sensitivity of simulated wind speed to spatial resolution over complex terrain. Enrgy Proc 59:323-329.

Goldman CR, Jassby A, 1990. Spring mixing depth as a determinant of annual primary production in lakes, p. 125-132. In: M.M. Tilzer and C. Serruya (eds.), Large Lakes. Brock/Springer Series in Contemporary Bioscience. Springer, Berlin.

Goto Y, Yasuda I, Nagasawa M, 2016. Turbulence estimation using fast-response thermistors attached to a free-fall vertical microstructure profiler. J. Atm. Ocean. Technol. 33:20652078.

Holzner CP, Aeschbach-Hertig W, Simona M, Veronesi M, Imboden D, Kipfer R, 2009. Exceptional mixing events in meromictic Lake Lugano (Switzerland/Italy), studied using environmental tracers. Limnol. Oceanogr. 54:1113-1124.

Hupfer M, Lewandowski J, 2008. Oxygen controls the phosphorus release from lake sediments - a long-lasting paradigm in limnology. Int. Rev. Hydrobiol. 93:415-432.

Imboden D, Stotz B, Wuest A, 1987. Hypolimnic mixing in a deep alpine lake and the role of a storm event. Int. Ver. Theor. Angew. 1922-2010:67-73.

Imboden DM, Lemmin U, Joller T, Schurter M, 1983. Mixing processes in lakes: mechanisms and ecological relevance. Schweiz. Z. Hydrol. 45:11-44.

Krishna S, Ulloa HN, Kerimoglu O, Minaudo C, Anneville O, Wüest A, 2021. Model-based data analysis of the effect of winter mixing on primary production in a lake under reoligotrophication. Ecol. Modell. 440:109401.

Laborde S, Antenucci J, Copetti D, Imberger J, 2010. Inflow intrusions at multiple scales in a large temperate lake. Limnol. Oceanogr. 55:1301-1312.

Lane A, 1989. The heat balance of the North Sea. Report No. 8. Proudman Oceanographic Laboratory, Liverpool: 46 pp.

Lau M, Valerio G, Pilotti M, Hupfer M, 2020. Intermittent meromixis controls the trophic state of warming deep lakes. Sci. Rep. 10:12928.

Lenstra WK, Hahn-Woernle L, Matta E, Bresciani M, Giardino C, Salmaso N, Musanti M, Fila G, Uittenbogaard R, Genseberger M, van der Woerd HJ, Dijkstra HA, 2014. Diurnal variation of turbulence-related quantities in Lake Garda. Adv. Ocean. Limnol. 5:184-203.

Lepori F, Bartosiewicz M, Simona M, Veronesi M, 2018. Effects of winter weather and mixing regime on the restoration of a deep perialpine lake (Lake Lugano, Switzerland and Italy). Hydrobiologia 824:229-242.

Lesser GR, Roelvink J v, Van Kester J, Stelling G, 2004. Development and validation of a three-dimensional morphological model. Coast. Engin. 51:883-915. 
Lincoln BJ, Rippeth TP, Lenn YD, Timmermans ML, Williams WJ, Bacon S, 2016. Wind-driven mixing at intermediate depths in an ice-free Arctic Ocean. Geophys. Res. Lett. 43:9749-9756.

Meybeck M, Blanc P, Moulherac AE, Corvi C, 1991. Chemical evidence of water movements in the deepest part of Lake Leman (Lake Geneva). Aquat. Sci. 53:273-289.

Michalski J, Lemmin U, 1995. Dynamics of vertical mixing in the hypolimnion of a deep lake: Lake Geneva. Limnol. Oceanogr. 40:809-816.

Mortimer CH, 1974. Lake hydrodynamics. Int. Verein. Theor. Angew. Limnol. Mitteil. 20:124-197.

Nash JD, Caldwell DR, Zelman MJ, Moum JN, 1999. a thermocouple probe for high-speed temperature measurement in the ocean. J. Atm. Ocean. Technol. 16:1474-1482.

North RP, North RL, Livingstone DM, Köster O, Kipfer R, 2014. Long-term changes in hypoxia and soluble reactive phos- phorus in the hypolimnion of a large temperate lake: consequences of a climate regime shift. Global Change Biol. 20:811-823.

Peeters F, Finger D, Hofer M, Brennwald M, Livingstone DM, Kipfer R, 2003. Deep-water renewal in Lake Issyk-Kul driven by differential cooling. Limnol. Oceanogr. 48:1419-1431.

Piccolroaz S, Amadori M, Toffolon M, Dijkstra, HA, 2019. Importance of planetary rotation for ventilation processes in deep elongated lakes: Evidence from Lake Garda (Italy). Sci. Rep. 9:8290.

Piccolroaz S, Woolway RI, Merchant CJ, 2020. Global reconstruction of twentieth century lake surface water temperature reveals different warming trends depending on the climatic zone. Climatic Change 160:427-442.

Preusse M, Peeters F, Lorke A, 2010. Internal waves and the generation of turbulence in the thermocline of a large lake. Limnol. Oceanogr. 55:2353-2365.

Reiss RS, Lemmin U, Cimatoribus AA, Barry DA, 2020. Wintertime coastal upwelling in Lake Geneva: An efficient transport process for deep water renewal in a large, deep lake. J. Geophys. Res.-Oceans 125:e2020JC016095.

Rogora M, Buzzi F, Dresti C, Leoni B, Lepori F, Mosello R, Patelli M, Salmaso N, 2018. Climatic effects on vertical mixing and deep-water oxygen content in the subalpine lakes in Italy. Hydrobiologia 824:33-50.

Sadro S, Melack JM, Sickman JO, Skeen K, 2019. Climate warming response of mountain lakes affected by variations in snow. Limnol. Oceanogr. Lett. 4:9-17.

Salmaso N, 2005. Effects of climatic fluctuations and vertical mixing on the interannual trophic variability of Lake Garda, Italy. Limnol. Oceanogr. 50:553-565.

Salmaso N, Decet F, 1998. Interactions of physical, chemical and biological processes affecting the seasonality of mineral composition and nutrient cycling in the water column of a deep subalpine lake (Lake Garda, Northern Italy). Arch. Hydrobiol. 142:385-414.

Salmaso N, Mosello R, Garibaldi L, Decet F, Maria C, Brizzio P, Cordella P, 2002. Vertical mixing as a determinant of trophic status in deep lakes: A case study from two lakes south of the Alps (Lake Garda and Lake Iseo). J. Limnol. $62: 33-41$
Salmaso N, Boscaini A, Capelli C, Cerasino L, 2018. Ongoing ecological shifts in a large lake are driven by climate change and eutrophication: evidences from a three-decade study in Lake Garda. Hydrobiologia 824:177-195.

Schwefel R, Gaudard A, Wüest A, Bouffard, D, 2016. Effects of climate change on deepwater oxygen and winter mixing in a deep lake (Lake Geneva): Comparing observational findings and modeling. Water Resour. Res. 52:8811-8826.

Schwefel R, Müller B, Boisgontier A, Wuest A, 2019. Global warming affects nutrient upwelling in deep lakes. Aquat. Sci. 81:50.

Simona M, 2003. Winter and spring mixing depths affect the trophic status and composition of phytoplankton in the northern meromictic basin of Lake Lugano. J. Limnol. 62:190-206

Skamarock WC, Klemp JB, Dudhia J, Gill DO, Liu Z, Berner J, Wang W, Powers GJ, Duda MG, Barker DM, et al, 2008. A description of the Advanced Research (WRF) model, Version 3. University Corporation for Atmospheric Research, Boulder.

Socolofsky SA, Jirka GH, 1995. Environmental fluid mechanics 1: Mixing and transport in the environment. Texas A\&M University: $184 \mathrm{pp}$.

Sommer T, Carpenter JR, Schmid M, Lueck RG, Wüest A, 2013. Revisiting microstructure sensor responses with implications for double-diffusive fluxes. J. Atm. Ocean. Technol. 30:1907-1923.

Straile D, Jöhnk K, Henno R, 2003. Complex effects of winter warming on the physicochemical characteristics of a deep lake. Limnol. Oceanogr. 48:1432-1438.

Swann GEA, Panizzo VN, Piccolroaz S, Pashley V, Horstwood MSA, Roberts S, Vologina E, Piotrowska N, Sturm M, Zhdanov A, Granin N, Norman C, McGowan S, Mackay AW, 2020. Changing nutrient cycling in Lake Baikal, the world's oldest lake. P. Natl. Acad. Sci. USA 117:27211-27217.

Valerio G, Pilotti M, Barontini S, Leoni B, 2015. Sensitivity of the multiannual thermal dynamics of a deep pre-alpine lake to climatic change. Hydrol. Process. 29:767-779.

van Haren $\mathrm{H}$, Maas L, Zimmerman J, Ridderinkhof $\mathrm{H}$, Malschaert H, 1999. Strong inertial currents and marginal internal wave stability in the central North Sea. Geophys. Res. Lett. 26:2993-2996.

van Haren H, Piccolroaz S, Amadori M, Toffolon M, Dijkstra HA, 2021. Moored observations of turbulent mixing events in deep Lake Garda, Italy. J. Limnol. 80:1983.

Verburg P, Antenucci JP, Hecky, RE, 2011. Differential cooling drives large-scale convective circulation in Lake Tanganyika. Limnol. Oceanogr. 56:910-926.

Wolk F, Yamazaki H, Seuront L, Lueck, RG, 2002. A new freefall profiler for measuring biophysical microstructure. J. Atm. Ocean. Technol. 19:780-793.

Woolway R, Merchant C, 2003. Worldwide alteration of lake mixing regimes in response to climate change. Nat. Geosci. 12:271-276.

Wüest A, Lorke A, 2003. Small-scale hydrodynamics in lakes. Annu. Rev. Fluid Mech. 35:373-412. 